\title{
Avaliación do impacto do Programa Fondo Tecnolóxico 2007-2013 en Galicia: resultados, concentración das axudas e fugas de recursos
}

\author{
Diego Sande Veiga / Xavier Vence Deza* \\ Universidade de Santiago de Compostela - Facultade de Ciencias Económicas e Empresariais
}

Recibido: 29 de marzo de 2019 / Aceptado: 9 de setembro de 2019

\begin{abstract}
Resumo
Avalíase o impacto en Galicia da implementación do Programa Operativo para e polo beneficio da I+D+i empresarial-Fondo Tecnolóxico 2007-2013, que constituíu un instrumento singular das políticas de innovación financiado polos Fondos Estruturais da Unión Europea e dirixido ás comunidades autónomas españolas do Obxectivo Converxencia da Unión Europea. A través da análise proposta trátase de identificar o impacto deste Programa plurianual -que mobilizou un importante volume de recursos e cuxa execución se estende ata 2015- na evolución do Sistema Galego de Innovación. Con ese fin analízanse os diferentes tipos de medidas e actuacións financiadas e o seu impacto nos principais indicadores de innovación (creación de capacidades, gasto en investigación e desenvolvemento, solicitude de patentes, persoal en investigación e desenvolvemento, infraestruturas, redes de colaboración, etc.), contrastando os obxectivos perseguidos e os resultados observados. Tamén se analizan aspectos institucionais e organizacionais que inciden no deseño, implementación e xestión das medidas e a súa posible incidencia nos seus efectos (fugas de recursos, dificultades de vertebración, concentración das actividades innovadoras nun número limitado de axentes, etc.). As conclusións extraídas permiten formular recomendacións para o deseño e implementación no territorio doutras políticas de investigación, desenvolvemento e innovación.
\end{abstract}

\section{Palabras clave}

Políticas de I+D+i / Sistema Galego de Innovación / Fondo Tecnolóxico / Avaliación de políticas de innovación / Desenvolvemento rexional.

\section{Impact Evaluation of the Technology Fund Programme 2007-2013 in Galicia: Results, aid concentration and leakage of resources}

\section{Abstract}

The aim of this study is to evaluate the implementation and the impact in Galicia of the Operational Programme for the benefit of business, Research, Development \& Innovation-Technology Fund 2007-2013, which was a unique instrument of innovation policies financed by the European Union Structural Funds and addressed to the Spanish Autonomous Regions of the European Union Convergence Objective. Through the proposed analysis, we identify the impact of this Multiannual Programme -which mobilised a significant volume of resources and whose execution extends until 2015- on the evolution of the Galician Innovation System. To this end, the different types of measures and actions financed and their impact on the main innovation indicators (capacity building, Research \& Development expenditure, patent applications, Research \& Development personnel, infrastructures, collaboration networks, etc.) are analysed, contrasting the objectives pursued and the results observed. Institutional and organisational aspects that affect the design, implementation and management of measures and their possible impact on their effects (leakage of resources, vertebration difficulties, concentration of innovative activities in a limited number of agents, etc.) are also analysed. The conclusions make it possible to formulate recommendations for the design and implementation in the territory of other Research \& Development \& Innovation policies.

\section{Keywords}

R\&D\&I policies / Galician Innovation System / Technological Fund / Evaluation of innovation policies / Regional development.

JEL Codes: 032, 038, R58.

\footnotetext{
* Correspondencia autor: xavier.vence@usc.es
} 


\section{Introdución}

O Fondo Tecnolóxico (FT) é unha partida especial de Fondos FEDER da Unión Europea (UE) dedicada á promoción da investigación, desenvolvemento e innovación (I+D+i) empresarial posta en marcha no período 2007-2013 que presenta unha serie de singularidades que a converten en especialmente interesante para a súa análise e avaliación. Trátase dun programa plurianual específico para as comunidades autónomas (CC.AA.) españolas, e de xeito moi especial orientado ás CC.AA. incluídas no Obxectivo Converxencia (Galicia, Andalucía, Estremadura e Castela-A Mancha). É un Programa que nace precisamente para paliar en certa medida a redución progresiva dos recursos estruturais asignados ás CC.AA. españolas como consecuencia dos diferentes efectos da ampliación da UE. Dotouse desde a Unión Europea cunha partida especial e cun volume de recursos relativamente importante (aproximadamente 2.000 millóns de euros), e foi destinado a tratar de reducir as fraquezas do Sistema de Ciencia, Tecnoloxía e Empresa e a distancia que separa as rexións con máis atraso tecnolóxico respecto das máis desenvolvidas (Ministerio de Economía y Hacienda, 2007). Galicia, como Comunidade Autónoma Obxectivo Converxencia, é un dos territorios prioritarios e o seu FT específico dótase con 405 millóns de euros para todo o período.

A entrada en vigor do citado Programa, no período de programación 2007-2013, prodúcese cun certo atraso, de xeito que o inicio real coincide co estoupido da fonda crise do ano 2008. Ese contexto marcado pola fonda crise económica padecida vese agravado polas agresivas políticas de austeridade levadas a cabo, o que desbarata moitos plans, dificulta o cofinanciamento e, ademais, afecta profundamente ás capacidades e estratexias dos diferentes axentes do sistema de innovación (empresas, centros, universidades, sector financeiro, etc.).

O obxectivo desta investigación consiste en analizar a aplicación do Programa Operativo Fondo Tecnolóxico no Sistema Galego de Innovación, tendo en conta o devandito contexto. Desta maneira, estudamos en que medida a planificación, deseño e execución destes fondos tiveron un impacto na capacidade innovadora do tecido empresarial e do conxunto do sistema de innovación. Tratamos, así mesmo, de detectar en que medida a súa aplicación presentou problemas adicionais derivados do propio deseño e da xestión do Programa.

De acordo coas metodoloxías asentadas na literatura (Papaconstantinou e Polt, 1997), o obxectivo da avaliación centrarase na determinación da relevancia e os efectos da política avaliando dous aspectos principalmente: a distancia entre a política instrumentada e o plan inicial (eixe plan-política), e os efectos económicos xerados pola política executada (eixe política-efectos económicos). Porén, un proceso avaliador como o proposto non está exento de dificultades. Neste sentido é preciso distinguir entre un tipo de avaliación que busca a cuantificación precisa de acordo con modelos de causación lineal, e un tipo de avaliación realizada desde unha perspectiva sistémica. No primeiro caso, de acordo con Schmidt (2001), podemos identificar fundamentalmente tres grandes tipos de dificultades: 1) a dificultade para elixir formas axeitadas de medir efectos, sen as que non é posible decidir se un programa foi realizado con éxito; 2) a dificultade para medir os custos e os beneficios directos e indirectos dun programa, sen os que non é posible valorar de forma adecuada a eficiencia; e 3) a atribución causal do impacto dunha intervención política, sen a que non é posible avaliar de forma precisa unha política. Con todo, desde a nosa perspectiva, a avaliación dunha política dificilmente pode realizarse desde o marco estreito dunha causación lineal entre variables univocamente relacionadas. As medidas dunha política de innovación como esta teñen consecuencias non sobre un único tipo de axentes ou sobre unha única variable, senón que teñen efectos múltiples sobre unha diversidade de axentes e variables que compoñen o sistema de innovación. Nese sentido, a perspectiva da avaliación debe ser necesariamente sistémica, asumindo unha complexidade nas interaccións, con relacións de causalidade múltiples e con eventuais efectos de retroalimentación e unha certa indeterminación na intensidade deses efectos.

Este estudo elabórase coa seguinte estrutura. No apartado 2 exponse brevemente o enfoque dos sistemas rexionais de innovación e a súa relevancia para o deseño e avaliación das políticas de innova- 
ción a nivel rexional, así como as principais características do FT; no terceiro analízase a súa execución en Galicia, efectuando unha avaliación do impacto do Programa nos principais indicadores para o período 2007-2013, cunha referencia máis específica ao Programa FEDER-Innterconecta; e finalmente, no cuarto apartado extráense as conclusións e recomendacións que se derivan do estudo.

\section{A importancia dos Fondos Estruturais (FF.EE.) para a innovación e o desenvolvemento das rexións europeas}

Na literatura parece existir un consenso xeral que asocia os resultados de innovación das empresas con determinadas contornas territoriais e con políticas rexionais específicas (Asheim, 2006; Audretsch, 1998; Landabaso, 2011; McCann e Rodríguez-Pose, 2011). De feito, as políticas de desenvolvemento rexional veñen desempeñando un importante papel nos últimos anos e teñen incorporado programas especificamente orientados a promover a innovación e mesmo, como ocorre coas S3, tratan de incorporar a estratexia innovadora de xeito transversal. Con todo, o esforzo de avaliación destas políticas foi insuficiente.

0 certo é que, a pesar da importante dotación dos FF.EE., as desigualdades rexionais persisten no tempo (Breinlich, Ottaviano e Temple, 2014; Neumark e Simpson, 2015) e incluso estas desigualdades espaciais están crecendo dentro dos países da OCDE (Lembcke e Menon, 2017).

A pesar de que o impacto real do apoio da UE ás economías nacionais está aínda en discusión, a análise da literatura científica (Jurevičienè e Pileckaitè, 2013; Remeikiene e Gaspareniene, 2016) pon de manifesto que os fondos públicos, como os FF.EE., poden ter un impacto ambiguo na competitividade dos países que os absorben (Aiello e Pupo, 2012; Cardenete e Delgado, 2013; Dall'erba, Guillain e Le Gallo, 2009; Žalevičienè, 2012), de maneira que a efectividade dos FF.EE. dependería de como se realizase o seu investimento (Jurevičienè e Pileckaitè, 2013).

\subsection{A importancia do sistema rexional no deseño das políticas de innovación}

A innovación é un proceso de aprendizaxe no que as interaccións entre os diferentes axentes do sistema de innovación son claves, sobre todo para facilitar a circulación do coñecemento, razón pola que a proximidade dos axentes resultaría beneficiosa (Boschma, 2005; Cooke, 1998; Lundvall, 1992). A capacidade tecnolóxica das empresas é un factor fundamental á hora de levar a cabo con éxito proxectos tecnolóxicos. Esta obteríase mediante un proceso de acumulación de experiencia e cooperación (Ahn, Minshall e Mortara, 2015; Basile, 2012; Fornhal, Broekel e Boschma, 2011; Koschatzky, 1997).

Na literatura de sistemas rexionais de innovación está claramente asentada a idea de que a dimensión rexional permite definir políticas de innovación máis acaídas para apoiar a competitividade do seu tecido produtivo, debido a que conta cun mellor coñecemento das súas necesidades e capacidades, o que permite afinar os instrumentos e medidas para reforzar a interacción entre o tecido industrial e os demais elementos do sistema rexional de innovación (Brujin e Lagendijk, 2005; Cooke, 1998; Martin e Trippl, 2013; Vence, 1998, 2007). Así mesmo, existe un consenso xeneralizado de que non existe unha política de innovación estándar que poida ser aplicada a todo tipo de rexións (Asheim, Moodysson e Tödtling, 2011; Boschma, 2009; Camagni e Capello, 2012; Foray, David e Hall, 2009; Foray e Van Ark, 2007; Isaksen, 2001; McCann e Ortega-Argilés, 2011; Nauwelaers e Wintjes, 2003; Tödtling e Trippl, 2005). De feito, este tipo de análises deu lugar a unha nova xeración de políticas rexionais baseadas nas "estratexias de especialización intelixente", "afinadas" e baseadas nas especificidades, potencial de innovación, recursos e capacidades das rexións (Barca, 2009; Comisión Europea, 2010, 2011; OECD, 2011). A pesar disto, menos claro resulta definir que debe ser semellante e que diferente nestas políticas segundo o contexto (Martin e Trippl, 2013), ou como evitar que esa aposta por estra- 
texias de "especialización intelixente" poida descoidar os necesarios esforzos para impulsar a diversificación produtiva (Cooke, 2012, 2018).

\subsection{Programa Fondo Tecnolóxico 2007-2013 no contexto español e galego}

No proceso de elaboración da Programación plurianual para o período 2007-2013, e no contexto no que España ía deixar de ser o principal país perceptor de FF.EE., o Consello Europeo estableceu unha asignación adicional superior aos 2.000 millóns de euros de recursos FEDER para un Fondo Tecnolóxico destinado a mellorar a I+D por e para o beneficio das empresas, especialmente nas rexións Obxectivo Converxencia.

O FT, respondendo á filosofía dos FF.EE., debía dirixirse en maior medida a aqueles territorios que presentasen un menor nivel de desenvolvemento. En concreto, para acometer a "promoción de I+D+i empresarial", a asignación de recursos produciuse de acordo coas seguintes porcentaxes indicativas aprobadas polo Consello Europeo (Ministerio de Economía y Hacienda, 2007): o 70\% para as rexións Obxectivo Converxencia de Galicia, Andalucía, Estremadura e Castela-A Mancha; o 5\% para as phasing-out (efecto estatístico); o 15\% para as phasing-in (efecto crecemento); e o 10\% para as rexións con Obxectivo Competitividade. A distribución por CC.AA. planificouse de maneira proporcional ao seu gasto en I+D. Dotouse, xa que logo, este Programa Operativo con 405,59 millóns de euros para Galicia, dun total de 2.248,45 millóns de euros para o conxunto do Estado.

O Programa Operativo de I+D+i por e para o beneficio das empresas-Fondo Tecnolóxico naceu como unha ferramenta clave para superar as debilidades do Sistema de Ciencia-Tecnoloxía-Empresa (SCTE) e para estruturar este de modo que estivese en condicións de aproveitar as oportunidades económicas e sociais que ofrece o desenvolvemento tecnolóxico. As principais debilidades detectadas neste foron (Ministerio de Economía y Hacienda, 2007): a baixa consideración da I+D+i como elemento de competitividade por parte do empresariado, a insuficiente formación e capacitación de recursos humanos (RR.HH.) en I+D+i, a falta de recursos financeiros e de RR.HH. para innovar, a escasa cultura de colaboración entre os axentes innovadores (empresas, centros de investigación e universidades), o escaso coñecemento das actividades de transferencia da innovación, a falta de aproveitamento por parte das empresas do sistema público de I+D ou a falta de cooperación entre pemes para promover proxectos innovadores.

De acordo coa formulación xeral, as actuacións prioritarias do Programa debían responder á seguinte tipoloxía nos territorios Obxectivo Converxencia (Ministerio de Economía y Hacienda, 2007):

a) Actuacións dirixidas á vertebración do sistema (fomento da cooperación entre organismos públicos de investigación (OPI), centros tecnolóxicos e empresas, favorecendo a incorporación das pemes á actividade innovadora).

b) Creación e consolidación de centros tecnolóxicos e de centros de investigación orientados á investigación aplicada relacionada coas empresas.

c) Apoio á transferencia de resultados de investigación dos OPI ás empresas.

d) Accións dirixidas a atraer a actividade investigadora e innovadora fundamentalmente a pemes e axentes con escasa actividade de I+D+i. Entre estas actuacións non se excluía o apoio a proxectos de concorrencia competitiva.

Dado que nese marco temporal Galicia presentaba unha necesidade de desenvolvemento económico e unha situación de atraso tecnolóxico con respecto ás rexións máis avanzadas da UE (Hollanders, Es-Sadki e Kanerva, 2016), facíase necesario prestarlle especial atención á eficacia e eficiencia das políticas tecnolóxicas aplicadas no territorio.

Na práctica, o Fondo Tecnolóxico instrumentalizouse en Galicia fundamentalmente a través de diferentes actuacións como o apoio á construción de infraestruturas de I+D, a realización de grandes préstamos, proxectos de transferencia tecnolóxica en concorrencia competitiva como o programa 
Innterconecta, ou a compra pública innovadora. Como é preceptivo, tamén se incluía unha dotación específica para o "seguimento e avaliación das accións acometidas", o que resultaría, sen dúbida, un exercicio moi útil, pero do cal non existe constancia pública. Neste sentido, este traballo trata de acometer, desde unha perspectiva académica, ese labor.

\section{Avaliación do Programa do Fondo Tecnolóxico 2007-2013 en Galicia: obxectivos e resultados preliminares}

O estudo ten un carácter empírico, desde o punto de vista que analiza datos de execución do Programa Operativo Fondo Tecnolóxico e que foi realizado a partir dunha pluralidade de fontes de datos cuantitativos: datos sobre a execución do Programa Operativo Fondo Tecnolóxico, facilitados pola Subdirección General de Administración del FEDER; datos das diferentes estatísticas de I+D, innovación e patentes (Instituto Galego de Estatística [IGE], Instituto Español de Estadística [INE], Eurostat); da Consellería de Facenda da Xunta de Galicia; das Oficinas Española e Europea de Patentes e da Administración estatal; e, por último, datos das empresas participantes nas convocatorias FEDER-Innterconecta en Galicia elaborados a partir de informacións do Centro para el Desarrollo Tecnológico Industrial (CDTI) e outras construídas especificamente para esta investigación.

Para abordar este apartado, desagrégase a información en catro partes: nunha primeira abordarase a aplicación, xestión e execución do Fondo Tecnolóxico estudado; na segunda parte afóndase na súa avaliación a través dos resultados nos indicadores de contexto e estratéxicos recollidos no documento do Programa Operativo; na terceira avaliaremos de xeito específico o Programa FEDER-Innterconecta como peza fundamental do FT; e, na cuarta, faremos balance dos resultados observados.

\subsection{Aplicación, xestión e execución do Fondo Tecnolóxico}

O primeiro que cómpre analizar é a estrutura institucional posta en marcha para a implementación do FT. A principal característica do modelo de aplicación é a súa centralización e a complexidade da rede de organismos que interveñen nas distintas fases de xestión, ademais dos que participan na certificación, auditoría, seguimento e avaliación, e nas restantes fases do circuíto financeiro establecido.

A autoridade de xestión deste Programa operativo foi o Ministerio de Hacienda (en concreto a Subdirección General de Administración del FEDER) e o organismo operativo clave foi o CDTI. A rede tecida estivo composta, ademais, por unha serie de organismos intermedios encargados de xestionar os fondos e as diversas convocatorias. En concreto foron 14 os designados, todos eles pertencentes á Administración do Estado ${ }^{1}$.

Esa estrutura de xestión absolutamente centralizada, e a complexa rede de organismos estatais creada para acometer a execución do Fondo Tecnolóxico, unida a un contexto de fonda crise económica e recortes orzamentarios, acaba conducindo a que o nivel de execución de recursos en Galicia e no conxunto do Estado permanecese en niveis moi baixos ao longo da práctica totalidade do período 20072013. Tanto é así que, a falta de sete meses para a fin da súa elixibilidade, esta execución situábase en valores próximos ao 50\% (Sande Veiga, 2018). Esta situación foi curiosamente corrixida pola Administración estatal nos últimos meses cun aumento da cifra executada declarada na Comunidade Autónoma ata os 460,40 millóns de euros, superando mesmo a cifra asignada inicialmente. Unha vez revisadas as certificacións presentadas á Comisión Europea, a cifra finalmente aceptada no ano 2018 foi de

\footnotetext{
${ }^{1}$ CDTI; Dirección General de Industria; Dirección General de Política de las Pymes; Dirección General de Telecomunicaciones y Tecnologías de la Información; Red.es; EOI; ENISA; Sociedad Estatal de Atracción de Inversiones Exteriores; Dirección General de Investigación y Gestión del Plan Nacional de I+D+i; Dirección General de Transferencia de Tecnología y Desarrollo Empresarial; INIA; Consejo Superior de Cámaras de Comercio, Industria y Navegación de España; Instituto de Salud Carlos III; Dirección General de Cooperación Internacional y Relaciones Institucionales; ICEX; ADIF.
} 
407,06 millóns de euros. Desta forma de proceder dedúcese que o problema da execución non está tanto no axuste formal de contías como na forma e eficacia no emprego dos recursos.

Nas Figuras 1 a 4 inclúese a cantidade de fondos asignados e os finalmente declarados por comunidade autónoma. Resulta rechamante a disparidade de graos de execución declarada e, sobre todo, de sobreexecución declarada nalgunhas delas (en particular, Estremadura, Asturias, Murcia, Castela e León e a Comunidade Valenciana). No caso galego, o nivel de sobreexecución declarado tamén é importante $(12,3 \%)$, pero dentro dunha orde. Como veremos a continuación, a maior parte da sobreexecución concéntrase nas actuacións xestionadas polo CDTI e, particularmente, en axudas a I+DT de pemes.

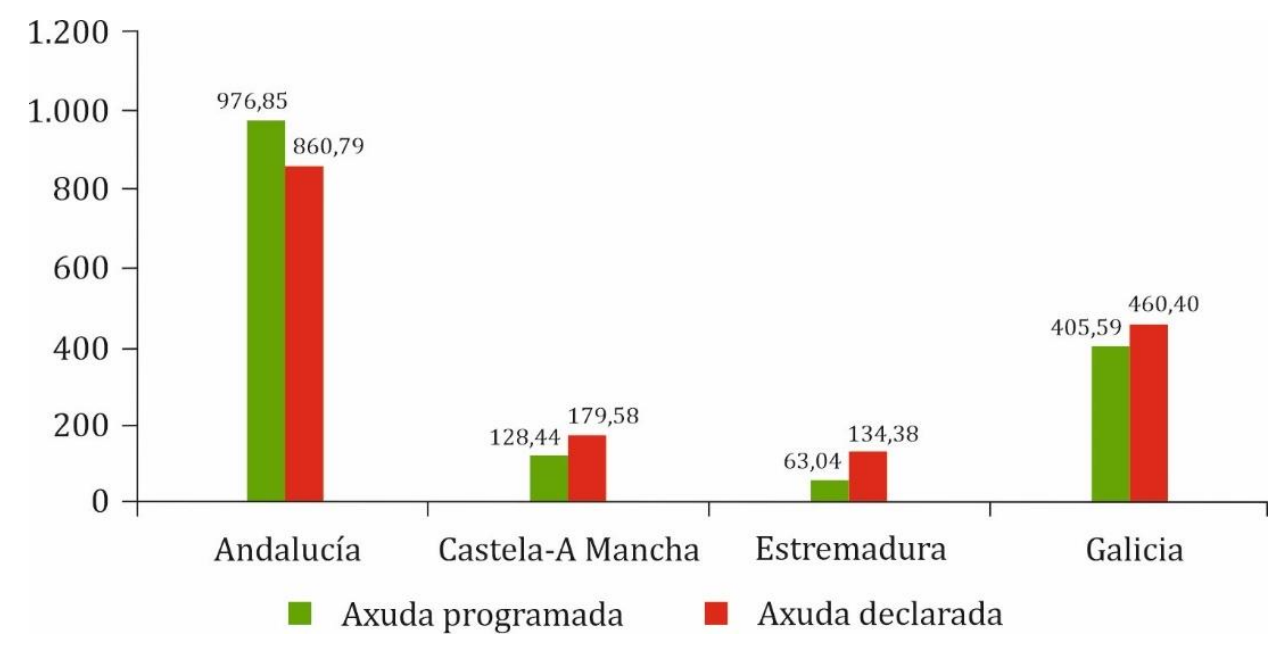

Figura 1. Axuda programada e declarada do Fondo Tecnolóxico, CC.AA. Converxencia (en millóns de euros). Fonte: elaboración propia a partir de datos do Ministerio de Hacienda y Administraciones Públicas (AA.PP.).

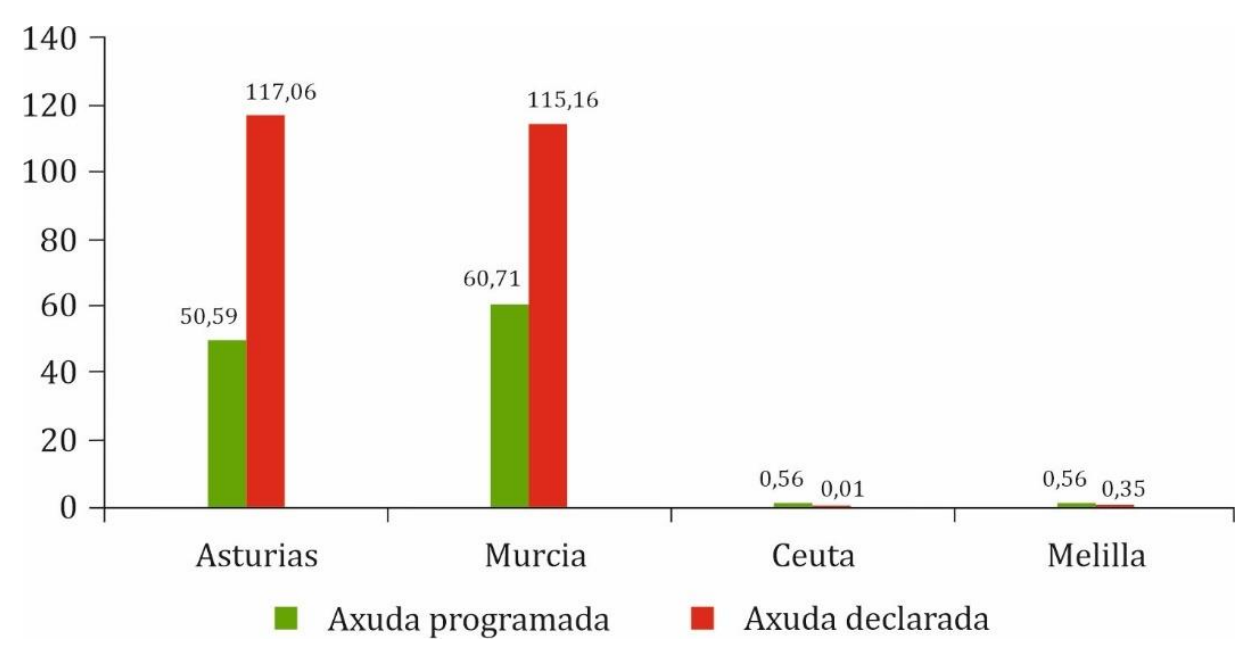

Figura 2. Axuda programada e declarada do Fondo Tecnolóxico, CCAA phasing-out (en millóns de euros). Fonte: elaboración propia a partir de datos do Ministerio de Hacienda y AA.PP. 


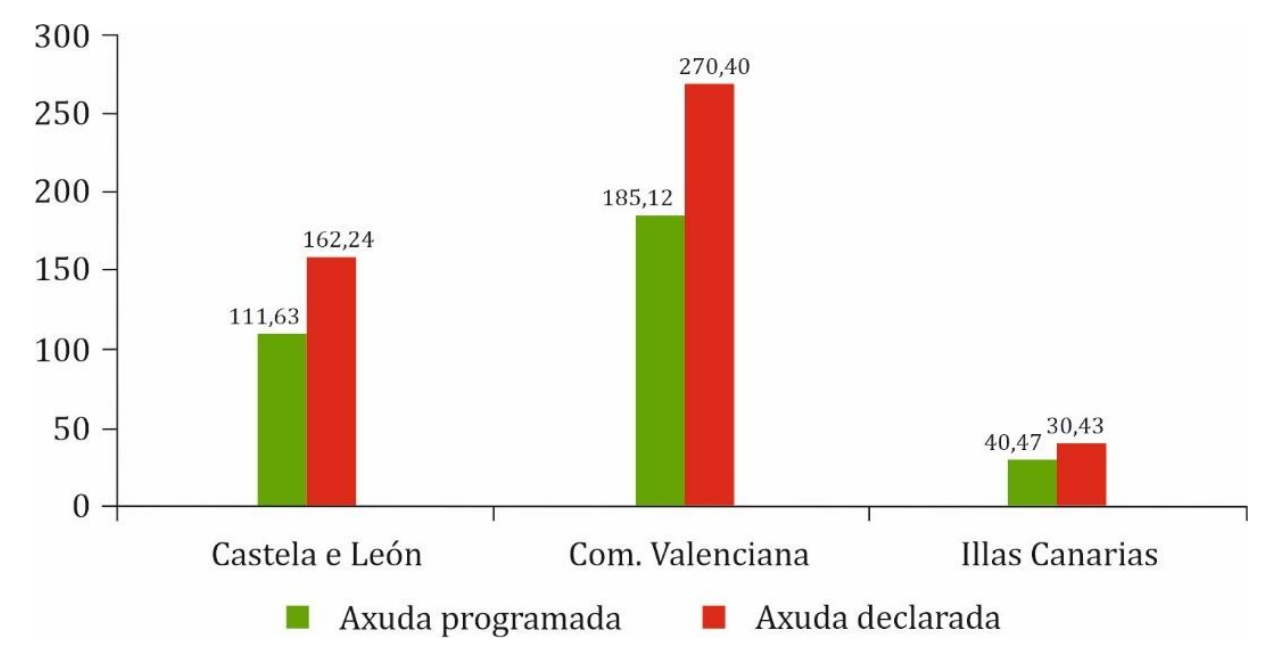

Figura 3. Axuda programada e declarada do Fondo Tecnolóxico, CC.AA. phasing-in (en millóns de euros). Fonte: elaboración propia a partir de datos do Ministerio de Hacienda y AA.PP.

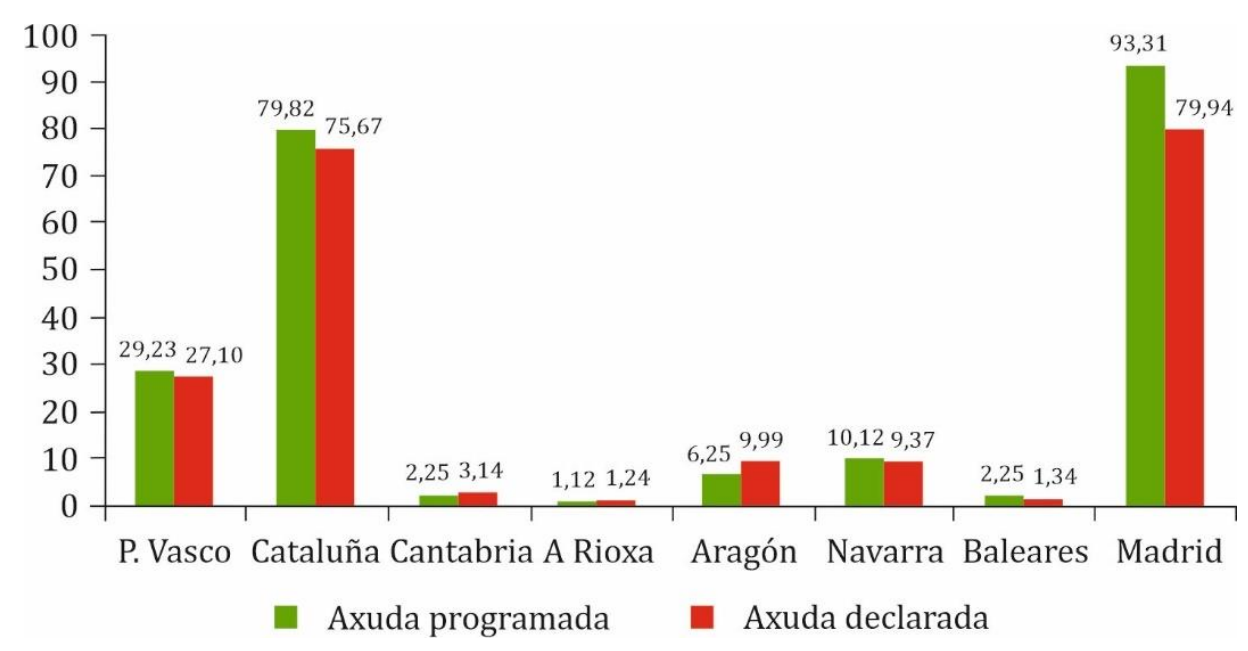

Figura 4. Axuda programada e declarada do Fondo Tecnolóxico, CC.AA. Competitividade (en millóns de euros). Fonte: elaboración propia a partir de datos do Ministerio de Hacienda y AA.PP.

No caso de Galicia, dos 17 xestores reais que finalmente levaron a cabo esta función, a maior parte dos recursos foron xestionados polo CDTI e pola Secretaría General de Ciencia e Innovación do Ministerio de Economía y Competitividad (MINECO), e xa a gran distancia polo Instituto de Crédito Oficial (ICO) e pola Agencia Estatal de Investigación. Case todos os organismos presentan graos de execución inferior ao previsto, con excepción de tres que declararon unha maior cantidade de axudas das previstas: o CDTI (84,36\% superior), a Agencia Estatal de Investigación (368,6\% superior) e a Dirección General de Industria y Pyme do Ministerio de Economía, Industria y Competitividad (411,34\% superior, aínda que con magnitudes absolutas moi exiguas). Ese resultado pode derivar da maior flexibilidade e capacidade de xestión do FT por parte destes entes públicos especializados nas axudas de I+D+i e que, ao xestionar tamén outros programas nese campo, teñen maior posibilidade de utilizalos para xustificar a execución de fondos europeos. Ningún dos restantes organismos xestores conseguiu acadar a execución programada. Entre estes, son tres nos que se concentra o groso de axudas que non foron aproveitadas: o ICO, a Secretaría General de Ciencia e Innovación e o nomeado Instituto Español de 
Oceanografía (IEO). En total, estes tres organismos non executaron o 16,66\% da asignación inicial do Fondo (Figuras 5 e 6).

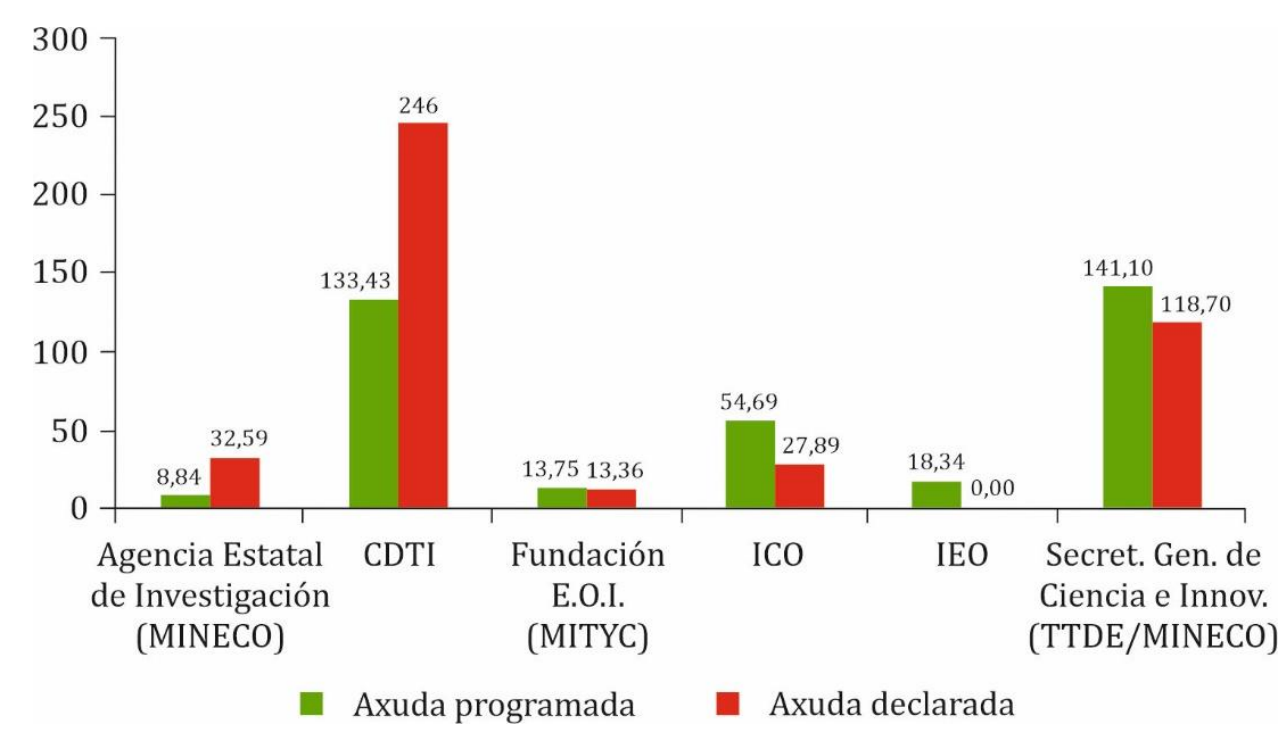

Figura 5. Fondo Tecnolóxico declarado en Galicia nos principais organismos xestores en contía (en millóns de euros). Fonte: elaboración propia a partir de datos do Ministerio de Hacienda y AA.PP.

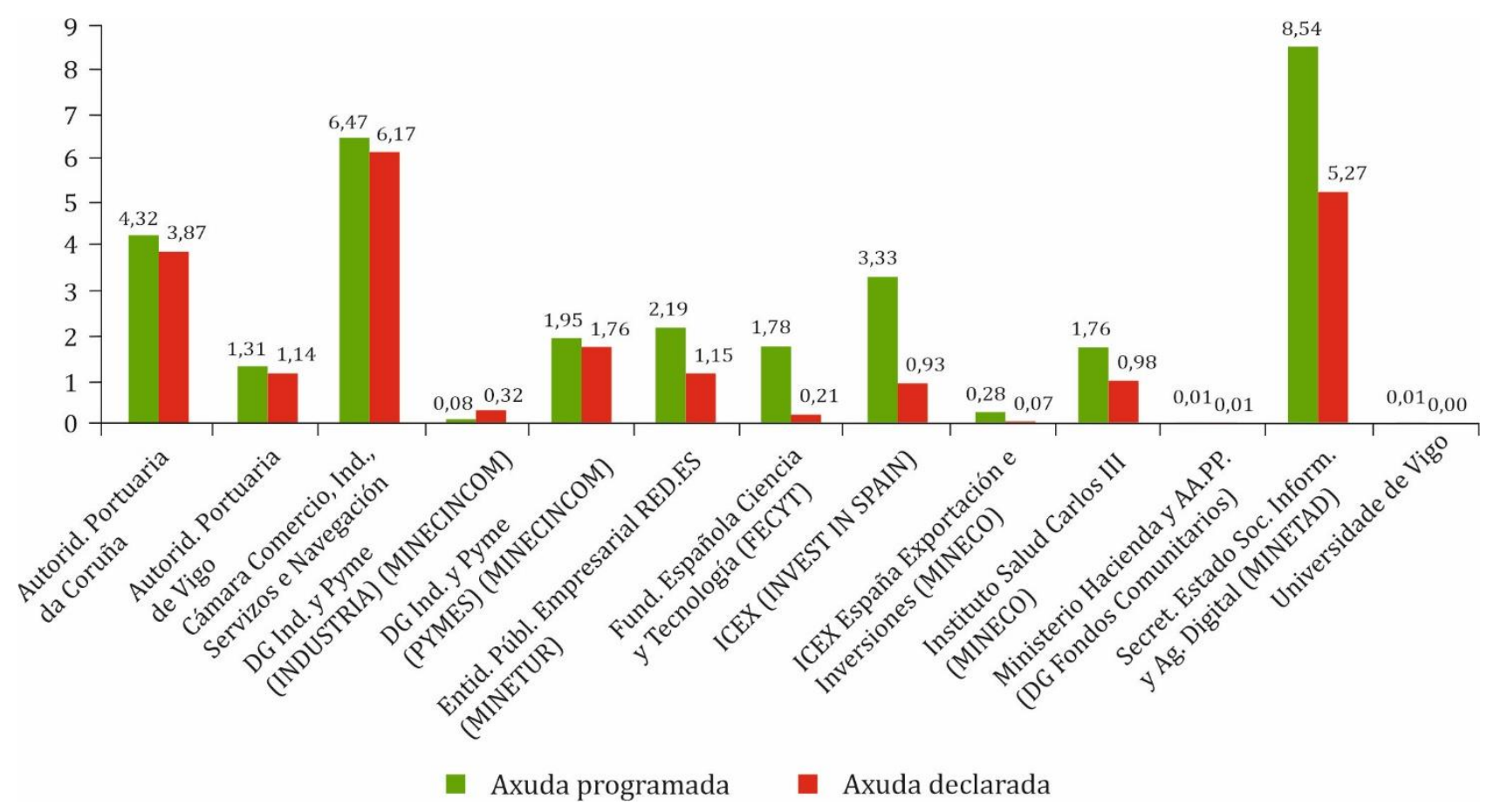

Figura 6. Fondo Tecnolóxico declarado en Galicia nos organismos xestores con menor contía (en millóns de euros). Fonte: elaboración propia a partir de datos do Ministerio de Hacienda y AA.PP.

O groso de axudas declaradas en Galicia centráronse no Eixe 1 do FEDER-Desenvolvemento da Economía do Coñecemento e, en particular, nos Temas 2, 4, 6 e 7 (ver Figura 7). 0 principal destino dos recursos foi: 
a) 0 Tema 4-Axudas a I+DT, especialmente a pemes, con 265,75 millóns de euros (o 57,72\% do total), corresponde en gran medida con actuacións e programas de axudas destinadas a proxectos para pemes e grandes empresas como Innterconecta ou as liñas de axuda de préstamos do ICO.

b) Séguelle o Tema 2-Infraestruturas de I+DT, con 96,52 millóns de euros (o 20,96\%), destinado a vertebrar a dotación de infraestruturas do Sistema Galego de Innovación. Incluíronse nel, finalmente, grandes proxectos como Hospital 2050 e Innova Saúde orientados principalmente á atención do paciente, mentres que outras actuacións previstas como a construción dun gran buque oceanográfico interrexional non amosaron resultados na frota do Instituto Oceanográfico. Dado o baixo nivel de execución do Programa Operativo durante a meirande parte do período analizado, tamén foron incluídas nel, finalmente, axudas a convenios que foron reprogramadas desde o Programa de Economía Baseada no Coñecemento, xa que o Fondo Tecnolóxico permitía o reembolso do $100 \%$ do investimento privado.

c) 0 Tema 7-Investimento en I+I das empresas con 40,39 millóns de euros (o 8,77\%).

d) E o Tema 6-Axudas a pemes para o fomento de produtos e procesos respectuosos co medio ambiente con 25,27 millóns de euros (o 5,49\%).

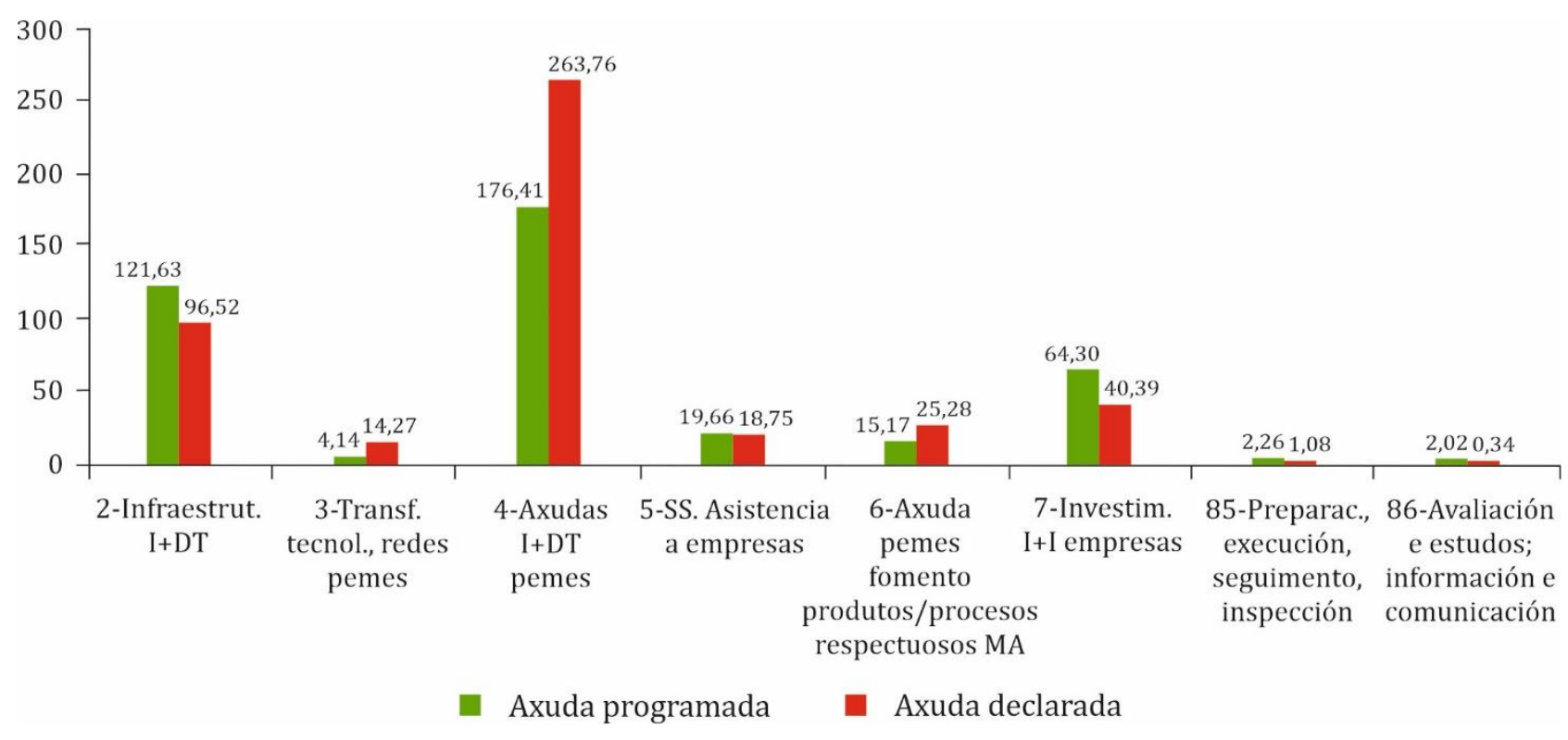

Figura 7. Axuda programada e declarada en Galicia do Fondo Tecnolóxico por Temas (en millóns de euros). Nota: os Temas 2 a 7 pertencen ao Eixe 1 destinado ao Desenvolvemento da Economía do Coñecemento, mentres que os Temas 85 e 86 pertencen ao Eixe 7 dedicado á Asistencia Técnica do Fondo Tecnolóxico. Fonte: elaboración propia a partir de datos do Ministerio de Hacienda y AA.PP.

\subsection{Avaliación de resultados: indicadores de contexto e estratéxicos}

O primeiro paso para a avaliación do FT consistirá en contrastar os obxectivos fixados no propio Programa para a batería de 13 indicadores de contexto e os 7 indicadores estratéxicos seleccionados cos resultados realmente observados ao final do período.

Na Táboa 1 e nas Figuras 8 e 9 podemos contrastar a evolución dos principais indicadores de contexto de I+D+i recollidos no Programa Operativo do Fondo Tecnolóxico para o período 2007-2013, no primeiro caso relativo ao conxunto español e no segundo relativo a Galicia. Incorporamos tamén os datos correspondentes ao ano 2015, na medida en que é o último ano de execución das actividades plurianuais aprobadas dentro do Programa. 
Táboa 1. Datos de evolución comparada dos principais indicadores de contexto de I+D+i en España e en Galicia relativos ao Fondo Tecnolóxico 2007-2013

\begin{tabular}{|c|c|c|c|c|c|c|}
\hline \multirow{2}{*}{ Indicadores } & \multicolumn{3}{|c|}{ España } & \multicolumn{3}{|c|}{ Galicia } \\
\hline & 2007 & 2013 & 2015 & 2007 & 2013 & 2015 \\
\hline Gasto I+D/PIB (\%) & 1,27 & 1,24 & 1,22 & 1,03 & 0,86 & 0,88 \\
\hline Gasto I+D das AA.PP./PIB (\%) & 0,22 & 0,29 & 0,23 & 0,14 & 0,13 & 0,14 \\
\hline Gasto I+D empresas e IPSFL/PIB (\%) & 0,69 & 0,67 & 0,64 & 0,54 & 0,39 & 0,39 \\
\hline Gasto I+D/Habitante $(€)$ & 295,18 & 279,30 & 283,80 & 202,30 & 170,20 & 182,20 \\
\hline Gasto I+D empresas-IPSFL/Total empresas (€) & $2.240,25$ & $2.201,75$ & $2.180,04$ & $1.871,17$ & $1.120,95$ & 911,27 \\
\hline Gasto I+D sectores alta tecnoloxía/Gasto I+D (\%) & 35,11 & 35,14 & 35,08 & 30,61 & 26,64 & 28,50 \\
\hline Persoal en I+D en EXC & 201.108 & 203.302 & 200.866 & 8.659 & 9.386 & 9.038 \\
\hline $\begin{array}{l}\text { Persoal en I+D en empresas e IPSFL /Persoal en I+D } \\
\text { EXC }(\%)\end{array}$ & 43,78 & 43,80 & 43,74 & 37,72 & 38,44 & 37,97 \\
\hline Persoal en I+D AA.PP./Persoal en I+D, EXC (\%) & 18,86 & 19,30 & 19,75 & 15,26 & 14,87 & 15,28 \\
\hline Investigadores/Persoal I+D EXC (\%) & 60,97 & 60,61 & 60,95 & 62,52 & 57,50 & 59,39 \\
\hline Graduados Univ. Ciencia e Tecnoloxía por 1.000 hab. & 7,50 & 13 & 19,14 & 7,40 & 14,60 & 16,48 \\
\hline Teses de doutoramento por 1.000 habitantes & 0,16 & 0,23 & 0,29 & 0,13 & 0,20 & 0,30 \\
\hline Solicitude de patentes (EPO)/Millón habitantes & 31 & 32,40 & 35,00 & 10,64 & 10,84 & 11,70 \\
\hline
\end{tabular}

Fonte: elaboración propia.

0 primeiro dato relevante é que para oito dos trece indicadores de contexto os valores de Galicia empeoran ao longo do período 2007-20132. No caso de España empeoran cinco dos trece indicadores.

Especialmente relevante é a caída experimentada no esforzo en I+D (investimento en I+D/PIB) en Galicia neste período -do 1,03\% ao 0,86\%, despois de ter acadado o 1,05\% no ano 2008-, nun período de declive tamén en España. Tomando como referencia o gasto en I+D por habitante, prodúcese un descenso tanto no ámbito español $(-15,88 €)$ como no galego $(-32,10 €)$; neste caso cómpre ter en conta que en Galicia a poboación permaneceu practicamente constante -aumenta arredor do $1 \%$ entre os anos 2007 e 2013 (INE, 2017)-, en tanto que no territorio español creceu arredor dun 6\%. No que se refire á distribución sectorial do gasto en I+D en Galicia, altérase parcialmente con respecto á distribución que había no ano 2007; cómpre sinalar un leve descenso no peso das AA.PP. e maior nas empresas (ao contrario do que sucede no caso español, no que aumenta o peso da compoñente pública). 0 cambio máis significativo é a caída do gasto medio en I+D por empresa (gasto I+D empresas/número total de empresas), que diminúe un 40,09\% en Galicia (un 1,72\% no conxunto do Estado español). Por outra banda, o gasto en sectores de alta tecnoloxía presenta cifras similares ao inicio e ao final de período, amosando peor comportamento en Galicia do que no conxunto do Estado.

Un dato positivo é o aumento do persoal destinado a actividades de I+D en Galicia, subindo este un 8,40\% no conxunto do período 2007-2013 (maior en todo caso que a suba do 1,09\% no conxunto estatal), aínda que volve caer entre os anos 2013 e 2015. Este incremento de persoal de I+D prodúcese principalmente nas empresas, xa que o persoal dedicado á I+D nas AA.PP. permanece relativamente estable (similar a como acontece no conxunto de España). Destaca o feito de aumentar o persoal técnico e auxiliar e a caída da proporción de investigadores con respecto ao total de traballadores dedicados á I+D.

Os tres indicadores que mostran un mellor comportamento neste período son indicadores de output: graduados en ciencias e tecnoloxías, teses de doutoramento e patentes. Galicia presenta mellor comportamento en número de graduados en ciencia e tecnoloxía e en número de teses de doutoramento con respecto ao conxunto do Estado. 0 número de patentes solicitadas á Oficina Europea de Pa-

\footnotetext{
${ }^{2}$ Dous deles equipáranse no ano 2015 (gasto en I+D das AA.PP. e proporción do persoal das AA.PP. sobre o total de persoal en $\mathrm{I}+\mathrm{D})$.
} 
tentes (ou PCT) mostra un comportamento moderadamente positivo na Comunidade Autónoma neses anos, aínda que sempre movéndose en valores moi modestos (cunha ratio que se mantén arredor dun terzo da media española e a enorme distancia da media comunitaria).

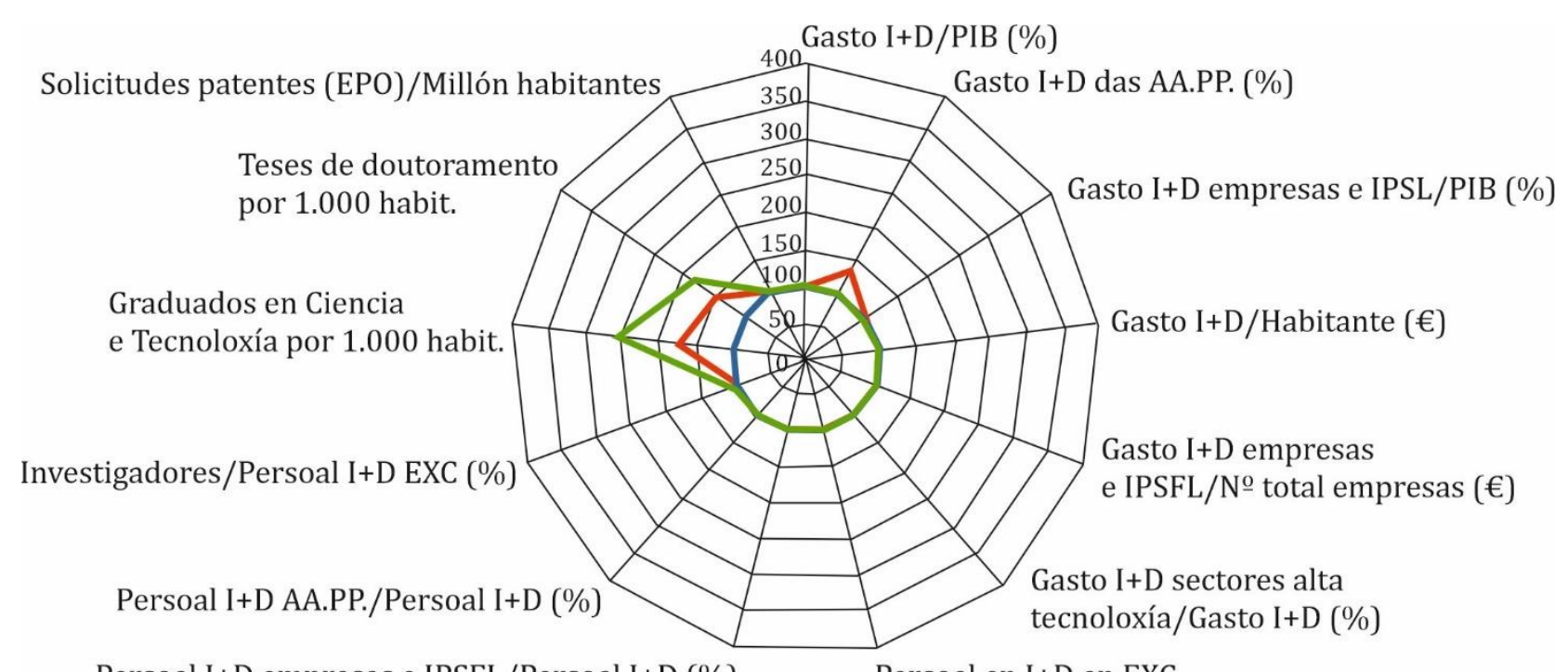

Persoal I+D empresas e IPSFL/Persoal I+D (\%)

Persoal en I+D en EXC

\section{— España 2007 - España 2013 - España 2015}

Figura 8. Evolución dos principais indicadores de contexto de I+D+i en España relativos ao Fondo Tecnolóxico 2007-2013 (\%, índice 2007=100). Nota: para os datos de teses de doutoramento tomouse o valor inicial do curso 2007-2008. Fonte: elaboración propia, datos de INE, IGE, Eurostat e Ministerio de Educación y Ciencia.

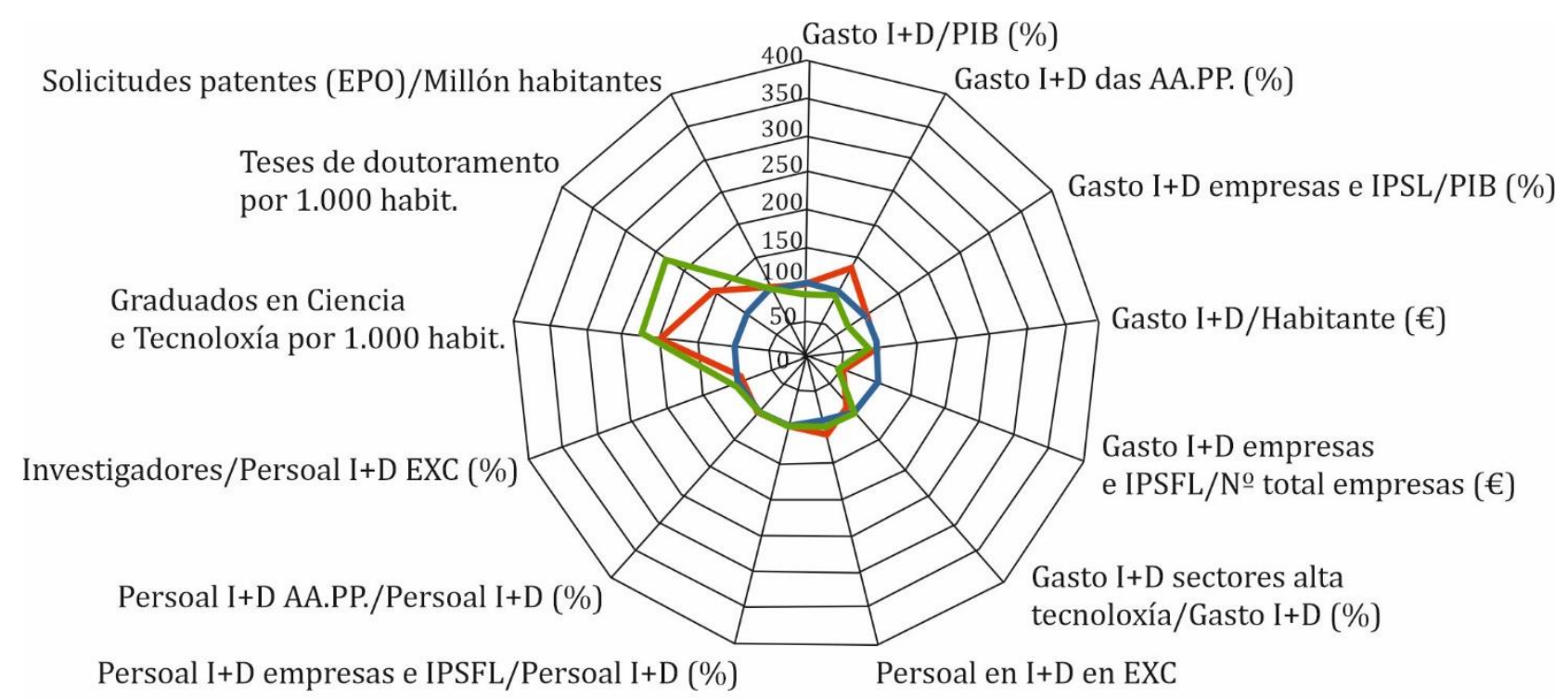

— Galicia 2007 — Galicia 2013 - Galicia 2015

Figura 9. Evolución dos principais indicadores de contexto de I+D+i en Galicia relativos ao Fondo Tecnolóxico 2007-2013 (\%, índice 2007=100). Nota: para os datos de teses de doutoramento tomouse o valor inicial do curso 2007-2008. Fonte: elaboración propia, datos de INE, IGE, Eurostat e Ministerio de Educación y Ciencia. 
Non obstante, a pesar da evolución positiva dos tres indicadores de output, é necesario concluír que a evolución xeral dos indicadores evidencia un comportamento contractivo do Sistema Galego de Innovación, sobre todo a partir do ano 2010. Así mesmo, en termos comparativos obsérvase que, de forma xeral, o comportamento dos indicadores no período foi mellor a nivel de España que en Galicia. Esta información estaría a poñer de manifesto que, a pesar dos recursos destinados para os territorios Obxectivo Converxencia mediante o Fondo Tecnolóxico, non se está a lograr o achegamento de Galicia á media española, e menos aínda aos territorios máis desenvolvidos en termos de I+D+i.

De maneira máis específica, para as rexións Obxectivo Converxencia fixáronse no documento do FT sete "indicadores estratéxicos" coas correspondentes previsións para o ano 2013: gasto I+D/PIB, solicitude de patentes (EPO)/millón de habitantes, solicitude de patentes EPO vinculadas ao sector do medio ambiente por millón de habitantes, teses de doutoramento aprobadas por 1.000 habitantes, mulleres traballando en I+D sobre o total de empregados en I+D (en EXC), porcentaxe de traballadores/traballadoras nos sectores de alta e media tecnoloxía e gasto en I+D do sector empresas e IPSFL/gastos I+D. Para cada un destes indicadores establecíase unha previsión cuantitativa de cara ao final do período 2007-2013 que podemos tomar como referencia para avaliar o impacto do FT. Polo tanto, contrastaremos os valores previstos polo FT para o ano 2013 cos valores deses indicadores ao inicio do período e en 2013. Así mesmo, teranse en conta tamén os datos reais de 2015, ano en que remata a execución do FT (ver Táboa 2 e Figuras 10 e 11).

Táboa 2. Datos de evolución comparada dos principais indicadores estratéxicos de I+D+i en España e en Galicia relativos ao Fondo Tecnolóxico 2007-2013

\begin{tabular}{|c|c|c|c|c|c|c|c|c|}
\hline \multirow[b]{2}{*}{ Indicadores } & \multicolumn{4}{|c|}{ España } & \multicolumn{4}{|c|}{ Galicia } \\
\hline & 2007 & $\begin{array}{l}\text { Previsión } \\
2013\end{array}$ & 2013 & 2015 & 2007 & $\begin{array}{l}\text { Previsión } \\
2013\end{array}$ & 2013 & 2015 \\
\hline Gasto I+D/PIB (\%) & 1,27 & 2,50 & 1,24 & 1,22 & 1,03 & 2 & 0,86 & 0,88 \\
\hline Gasto I+D empresas e IPSFL/Gasto I+D (\%) & 56,02 & 68,19 & 53,24 & 52,74 & 57,03 & 55,79 & 45,86 & 45,04 \\
\hline Teses de doutoramento por 1.000 habit & 0,16 & 0,27 & 0,23 & 0,29 & 0,14 & 0,19 & 0,20 & 0,30 \\
\hline Solicitude de patentes (EPO)/Millón habit. & 31 & 41,65 & 32,40 & 35,00 & 10,64 & 5,58 & 10,84 & 11,70 \\
\hline $\begin{array}{l}\text { Mulleres en I+D EXC do total empregados } \\
\text { en I+D EXC (\%) }\end{array}$ & 38,60 & 45 & 40,20 & 40,70 & 40,10 & 47,20 & 41,40 & 41,96 \\
\hline $\begin{array}{l}\text { Solicitude patentes (EPO) medio } \\
\text { ambiente/Millón habitantes }\end{array}$ & 0,51 & 0,15 & 1,69 & 1,12 & 0,59 & 0,74 & 0,59 & 0,62 \\
\hline Traballadoras alta e media tecnoloxía (\%) & 29 & 32 & 28,99 & 28,08 & 17,9 & 23,4 & $\mathrm{~N} / \mathrm{A}$ & $\mathrm{N} / \mathrm{A}$ \\
\hline
\end{tabular}

Fonte: elaboración propia ${ }^{3}$.

Como xa sinalamos, unha vía para a avaliación da calidade da programación e da eficacia da súa execución virá reflectida no grao de cumprimento deses obxectivos marcados polo propio Programa. De cumprirse os obxectivos previstos para o ano 2013 neses indicadores estratéxicos, a aplicación do Fondo Tecnolóxico debería permitir situar a Galicia e a España á altura dos territorios europeos máis dinámicos en canto a promoción, estímulo e realización de actividades innovadoras. Nas previsións realizadas do gasto en I+D con respecto ao PIB sería no exercicio 2013 do 2\% en Galicia e do 2,50\% no

\footnotetext{
3 Para o cálculo de patentes EPO empregáronse datos de Eurostat (inclúen EPO e PCT). Eurostat só ofrece valores para Galicia ata o ano 2012; tómase ese valor para os anos 2013 e 2015, supoñendo unha taxa de variación igual á española; para o cálculo de patentes europeas de medio ambiente tomáronse os valores dos informes de Tecnoloxías de mitigación do cambio climático da OEPM dos períodos 2004-2015 e 2005-2017. Ante a falta de valores por anos para Galicia, realizouse unha estimación para os anos 2013 e 2015 a partir da media anual dos períodos 2004-2015 e 2005-2017. 0 número de teses de doutoramento do ano 2007 corresponden ao curso 2007-2008 (Ministerio de Educación). Os restantes datos foron tomados do INE e do IGE.
} 
Estado español. Da mesma maneira, produciríase un claro incremento do gasto en I+D das empresas, atraídas por este esforzo no financiamento.

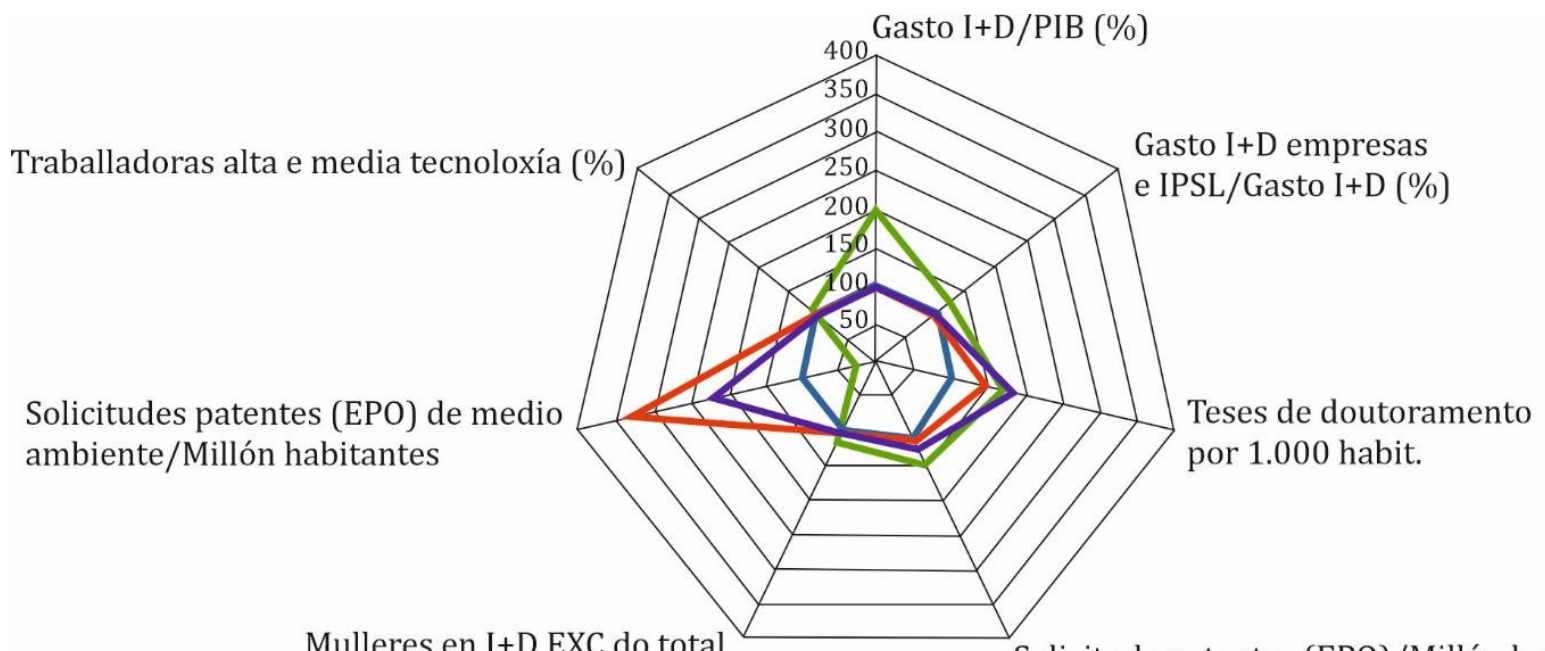

Mulleres en I+D EXC do total empregados en I+D EXC (\%)

Solicitude patentes (EPO)/Millón hatitantes

— España 2007 — Previsión España 2013 — España 2013 — España 2015

Figura 10. Evolución dos indicadores estratéxicos recollidos para España no P. O. Fondo Tecnolóxico, 2007-2013 (\%, índice 2007=100). Nota: dato de 2013-2015 non dispoñible. Fonte: elaboración propia.

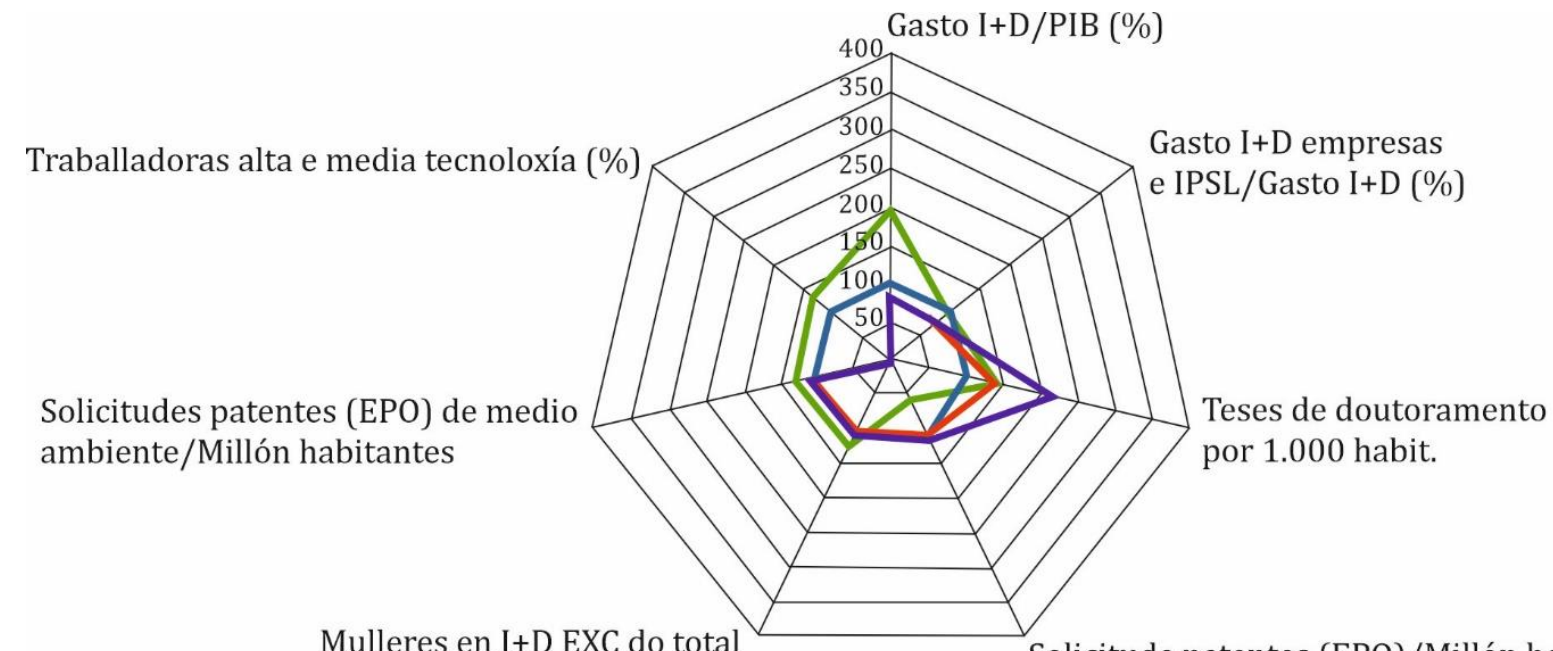

Mulleres en I+D EXC do total empregados en I+D EXC (\%)

Solicitude patentes (EPO)/Millón hatitantes

— Galicia 2007 — Previsión Galicia 2013 - Galicia 2013 Galicia 2015

Figura 11. Evolución dos Indicadores estratéxicos recollidos para Galicia no P. O. Fondo Tecnolóxico, 2007-2013 (\%, índice $2007=100$ ). Nota: dato de 2013-2015 non dispoñible. Fonte: elaboración propia.

Aínda que, como podemos observar, nalgúns dos indicadores houbo progresos, o certo é que os cálculos foron excesivamente optimistas, permanecendo a maioría dos valores moi por baixo do agarda- 
do, en especial no esforzo en $\mathrm{I}+\mathrm{D}$, na proporción do gasto empresarial en $\mathrm{I}+\mathrm{D}$ e nos indicadores de igualdade de xénero. Só dous dos obxectivos previstos se cumpriron en Galicia: o número de teses de doutoramento e o número de solicitudes de patentes europeas (EPO e PCT), se ben os valores acadados para este último indicador son moi modestos. Como logo veremos, son diversas as causas que poden explicar ese resultado pero, sen dúbida, podemos avanzar que unha delas é o moi baixo nivel de execución ao longo de case todo o período do Fondo Tecnolóxico e dos demais Fondos FEDER en Galicia, en particular nos programas operativos de carácter plurirrexional. De feito, de acordo coa información facilitada polo CDTI á altura de mediados de 2015, ano e medio despois de finalizado o seu prazo de vixencia, tan só a metade dos recursos do Fondo Tecnolóxico foran executados.

Debe advertirse que para un dos obxectivos (número de traballadoras en alta e media tecnoloxía en Galicia) non dispoñemos de datos, o que en si mesmo constitúe un elemento revelador da calidade do proceso de programación, ao establecer indicadores estratéxicos para os que non se dispón de información estatística.

\subsection{Análise da execución das convocatorias FEDER-Innterconecta}

Para afondarmos na avaliación da implementación do FT analizamos con maior detalle o programa FEDER-Innterconecta, tanto pola importancia da súa contía como pola natureza de apoio directo á I+D+i empresarial, a diferenza doutras actuacións do Fondo Tecnolóxico.

Ante a baixa execución do FT durante os primeiros anos de vixencia, activáronse na segunda metade do período de programación iniciativas como as convocatorias Innterconecta (nos anos 2011 e 2013), nas que se puxo o foco no investimento en grandes proxectos dirixidos principalmente por grandes empresas. Estas convocatorias naceron dirixidas de maneira específica a rexións Obxectivo Converxencia. A través deste instrumento conseguiuse elevar o nivel de execución do gasto do Programa, pero os obxectivos formulados diferiron das previsións realizadas e con respecto ás necesidades do tecido produtivo galego.

Desta maneira, unha parte importante dos recursos do FT foron destinados ás dúas primeiras convocatorias de FEDER-Innterconecta, que apoiaron proxectos integrados de desenvolvemento experimental nos que se fomentaba a cooperación estable público-privada, con carácter estratéxico, gran dimensión e que tivese como obxectivo o desenvolvemento de tecnoloxías innovadoras en áreas tecnolóxicas de futuro con proxección económica e comercial a nivel internacional.

Os proxectos deste Programa podían abordar calquera área temática sempre que estimulasen a creación de emprego, que tivesen un elevado nivel tecnolóxico e que lles permitisen aos participantes aumentar o valor engadido das súas actividades. Este Programa tamén podía apoiar proxectos de investigación industrial (CDTI, 2013).

A relevancia destas liñas de axuda Innterconecta é evidente se temos en conta que as contías destinadas nos anos 2011 e 2013 sumaban 262 millóns de euros para os territorios do Estado con Obxectivo Converxencia que finalmente participaron nel: Galicia contou con 105 millóns nas súas dúas primeiras convocatorias (cofinanciadas nun 20\% pola Comunidade Autónoma), Andalucía 150 millóns e Estremadura 7 millóns. Os recursos estaban destinados principalmente a cubrir custos de equipamento e instrumental, gastos de persoal, custos de investigación contractual, coñecementos técnicos e patentes, e outros custos de funcionamento (materiais, subministracións e outros).

Para ser beneficiario deste Programa requiriuse a formalización dunha agrupación de interese económico (AIE) ou consorcio, constituído como mínimo por tres empresas autónomas entre si, das que unha delas debería ser grande ou mediana e a outra pequena ou mediana, sendo necesaria a participación significativa, cando menos, dun organismo de investigación baixo a modalidade de subcontratación por parte dunha ou de varias das empresas integrantes. Un trazo anovador destas convocatorias analizadas é que permitían que se puidesen subcontratar organismos de investigación que realizasen parte das actividades fóra do territorio, sempre que estas fosen vitais para o seu desenvolvemento. De igual maneira, podían formar parte das agrupacións ou consorcios empresas que desenvolvesen a súa 
actividade noutras comunidades, sen establecer limitación na orixe ou no seu domicilio. Na práctica estas dúas cláusulas rompían o criterio de territorialidade e permitían destinar recursos a territorios diferentes dos inicialmente establecidos.

\subsubsection{As redes de colaboración conformadas}

A través deste Programa o número de proxectos aprobados en Galicia foi de 105, dun total de 210 solicitados, sendo o total de axentes participantes de forma directa de 752 (470 empresas e 282 organismos de investigación) (ver Táboa 3).

Táboa 3. Datos sobre o número de proxectos aprobados en Innterconecta I e Innterconecta II-Galicia

\begin{tabular}{lccc}
\hline & Proxectos aprobados & 1a convocatoria & 2 a convocatoria \\
\hline Número de proxectos & 105 & 26 & 79 \\
Número de empresas & $470^{*}\left(57^{* *}\right)$ & 107 & 363 \\
Número de organismos de investigación & 282 & 69 & 213 \\
\hline
\end{tabular}

*0 no de empresas foi de 369 na 2aㅡ convocatoria: 6 resultaron inactivas, quedando 363. **Número de empresas con domicilio social fóra de Galicia. Fonte: elaboración propia a partir de datos do CDTI, ITC 2012-2013-2014.

Resulta interesante analizar a tipoloxía de axentes participantes nos proxectos/redes en función da súa natureza (empresa ou centro tecnolóxico/organismo de investigación) e do seu tamaño. 0 número medio de participantes por proxecto foi de 7,17, sendo as empresas 4,48 e os organismos de investigación 2,69. Diferenciando as empresas por tamaño, o 66,60\% son pemes, mentres que o 33,40\% restante son grandes empresas. Dentro de cada proxecto as empresas participantes poden ter roles diferenciados, distinguindo entre empresas líderes ou representantes e empresas socias. As primeiras son as que teñen un papel de maior protagonismo e responsabilidade á hora de xestionar os proxectos, sendo tamén maior a contía que lles corresponde das axudas públicas concedidas. As empresas foráneas apenas representaban de forma xeral a unha de cada dez participantes, pero o seu número supuxo arredor dunha de cada catro nas empresas líderes.

En canto á participación de organismos de investigación (282 grupos), vemos que responden á seguinte tipoloxía: o $43,97 \%$ son universidades ou centros pertencentes a elas; o $27,66 \%$ son centros públicos de investigación; o 26,95\% son centros de investigación e tecnoloxía; e o 1,42\% serían outros organismos de investigación.

\subsubsection{A execución do programa FEDER-Innterconecta e a territorialidade dos axentes participantes: as fugas de recursos}

Este programa defínese como "subvencións para a Comunidade Autónoma de Galicia" que "supoñan un avance tecnolóxico e industrial relevante". Porén, a presenza dun certo número de empresas non galegas nas redes dos proxectos obrigou a analizar con máis detalle este aspecto. Co obxecto de determinar como se concretou esta realidade estudouse o lugar de desenvolvemento dos proxectos e o domicilio social das empresas participantes; a cuestión do domicilio é relevante se temos en conta que os centros de innovación están habitualmente ligados á sede das empresas.

Do estudo do domicilio social das empresas participantes despréndese que das 476 empresas inicialmente involucradas en Innterconecta, o 88,03\% tiñan domicilio social en Galicia, e "só" o 11,97\% fóra da Comunidade Autónoma. 0 certo é que a colaboración entre empresas de diferentes territorios pode ser enriquecedora para o intercambio de coñecemento, pero a valoración desa colaboración varía en función do rol de cada quen e, sobre todo, do liderado dos proxectos. Nese sentido, o feito diferen- 
cial prodúcese entre as 105 empresas líderes dos proxectos (non se tratarían só de colaboracións excepcionais): aquí o 76,19\% desas empresas líderes contaban con domicilio social en Galicia, mentres que o $23,81 \%$ son de fóra de Galicia. En termos de recursos, iso tradúcese en que da cantidade total de axudas finalmente concedidas (102,79 millóns de euros), case unha cuarta parte (23,87 millóns) corresponden a proxectos xestionados por empresas líderes con domicilio social e centros innovadores fóra de Galicia. Destaca singularmente o peso das grandes empresas da Comunidade de Madrid que lideran o $16,19 \%$ dos proxectos (Figura 12).

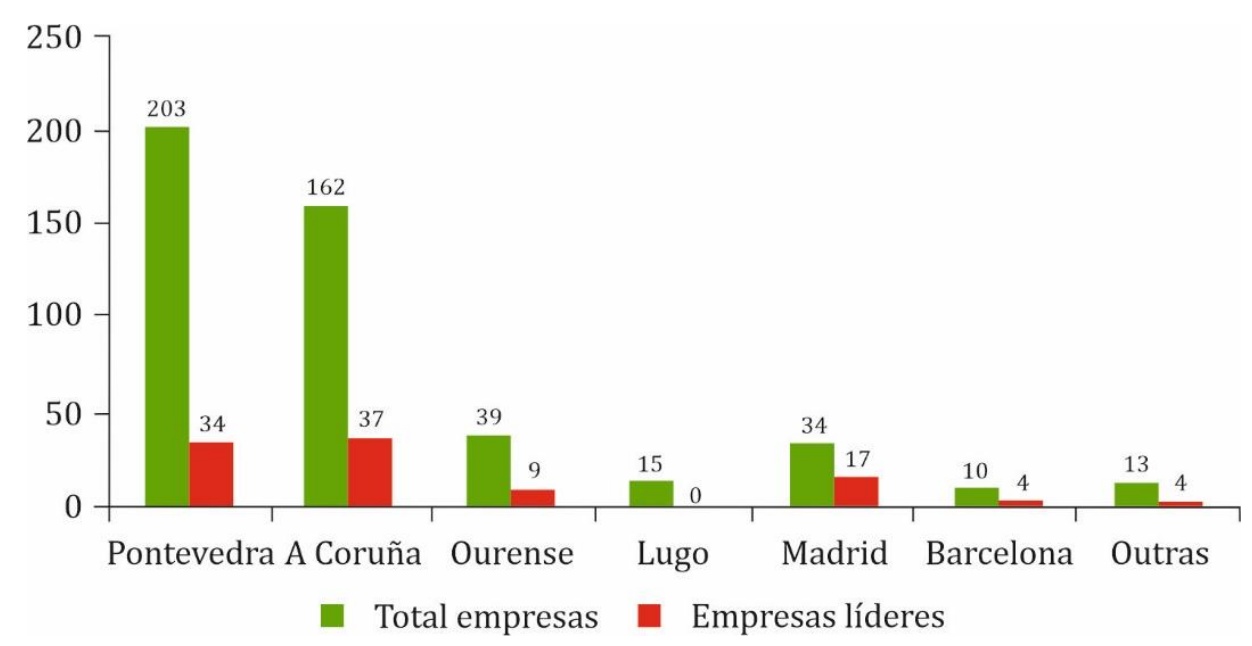

Figura 12. Domicilio social de empresas participantes nos proxectos aprobados de Innterconecta I e II-Galicia por provincias. Fonte: elaboración propia a partir de datos de CDTI, ITC 2013-2014.

Igualmente interesante resulta comprobar o elevado número total de empresas participantes foráneas tanto líderes como socias dos proxectos aprobados: no 44,76\% do total. Esa mesma proporción é a que representa o orzamento das axudas percibidas por estes proxectos participados por empresas de fóra de Galicia (o 43,58\%).

A constatación desta sorprendente participación de empresas de territorios diferentes aos da Comunidade Autónoma destinataria do FT ten una gran relevancia e merece unha reflexión. Como primeira consideración cómpre insistir en que este Programa se define como "subvencións para a Comunidade Autónoma de Galicia". Ademais da cuestión do domicilio social das empresas e da situación no territorio dos centros de innovación destas, as grandes empresas foráneas que participan nos proxectos empregan en numerosas ocasións delegacións ou filiais con diferente CIF que si poden estar localizadas na Comunidade Autónoma, pero cuxa coordinación, centros de innovación e xestión última pertencen á central radicada tamén noutro territorio (de aí a ligazón con ese domicilio social).

A magnitude cuantitativa e cualitativa desa participación de empresas foráneas obriga a cuestionar tanto as causas como as consecuencias desta. Parece bastante obvio que asignar recursos do FT de Galicia a proxectos liderados por empresas de fóra da Comunidade Autónoma ou con centros de innovación noutros territorios non é a vía para reforzar o Sistema Galego de Innovación. Tampouco se contribúe a reducir as disparidades rexionais se esas empresas pertencen precisamente á rexión coa maior capacidade de I+D e innovación. Pola contra, ese fluxo non só se traduce nunha fuga de recursos monetarios, senón que se converte nun fluxo dos retornos dos proxectos innovadores e do coñecemento xerado.

Esta presenza tan relevante de grandes empresas madrileñas no liderado dos proxectos ou na distribución dos fondos parece gardar unha estreita relación coa estrutura de xestión centralizada do 
Programa e a complexa rede establecida, que acabaron arrastrando problemas e atrasos na execución do FT, unidos á natureza socioeconómica da relación centro-periferia en España (o peso e a influencia das grandes empresas madrileñas na maior parte dos sectores). De feito, o atraso extraordinario na execución do FT foi un argumento utilizado para abrir a convocatoria a empresas doutros territorios. A forma de xustificar finalmente o uso dos fondos permite pensar que había unha estratexia non explicitada nesa dirección por parte dos xestores centrais.

Abunda nesa percepción a dobrez que sobre esta materia mostran os organismos xestores. Efectivamente, na análise do lugar de desenvolvemento dos proxectos, o CDTI non identificou ningunha actividade localizada de forma principal noutra comunidade autónoma. Segundo este organismo, o 100\% dos proxectos desenvólvense en Galicia, feito que contrasta coas informacións dispoñibles do domicilio das empresas e dos seus centros innovadores que acabamos de ver. Por este motivo deberíase valorar a realización de controis en maior profundidade sobre esta cuestión.

\subsubsection{Existe atracción de filiais de multinacionais e grandes empresas ou conformación de centros de in- novación empresarial?}

Unha cuestión ben diferente sería se o FT tivese actuado como instrumento de atracción de empresas tecnolóxicas ou de centros tecnolóxicos de empresas grandes e/ou de multinacionais. A importancia destas variables radica na actual necesidade de progresar na mellora das capacidades innovadoras e na conformación dun Sistema Galego de Innovación que aínda non acadou a súa madureza.

En canto á localización ou asentamento de multinacionais e de grandes empresas en Galicia atraídas polo esforzo efectuado a través do FT, non se observan resultados. Non se detectaron cambios de domicilio das empresas que participan das axudas cara a Galicia. Esta modificación de domicilio amosábase como altamente improbable tendo en conta que no deseño desta convocatoria permitíase a colaboración e o liderado de empresas doutros territorios.

No referido á creación de centros de I+D+i propios das empresas, non se pode afirmar que como resultado directo do Programa estudado se detectase, polo tanto, ningunha creación deste tipo de unidades en Galicia.

\subsection{Balance dos resultados da execución do FT}

A análise cuantitativa do FT evidencia unha considerable distancia entre os obxectivos establecidos e as realizacións observadas ao final do período. Nas previsións realizadas, para o gasto en I+D con respecto ao PIB establecíase que no exercicio 2013 Galicia alcanzaría o 2\% e o Estado español o 2,5\%. Da mesma maneira, produciríase un claro incremento do gasto en I+D das empresas, atraídas por este esforzo público adicional no financiamento. Como puidemos comprobar, os obxectivos previstos para os indicadores estratéxicos en Galicia foron excesivamente optimistas. Só dous dos obxectivos se cumpriron: o número de teses de doutoramento realizadas en Galicia e, modestamente, o número de patentes europeas. 0 resto dos valores quedan moi por baixo do agardado: na cifra de mulleres empregadas en I+D o valor final foi aproximadamente inferior nun $13 \%$ respecto do previsto, mentres que no gasto en I+D das empresas a diferenza aumenta ata preto do 19\%. Para o gasto en I+D galego/PIB, a situación mesmo empeorou, quedando os valores nun $43 \%$ do previsto.

Tal e como se establecía no documento do FT, a súa execución debía achegar a Galicia e a España á altura dos territorios europeos máis dinámicos en canto a promoción, estímulo e realización de actividades innovadoras. Despois do contraste realizado parece claro que esta situación non se produciu, permanecendo a unha clara distancia. Con todo, é tamén de xustiza indicar que algunhas melloras si se lograron, entre elas o incremento do número de solicitudes de patentes ata o ano 2016, o aumento da cifra de teses de doutoramento por cada mil habitantes e a leve mellora da proporción de mulleres empregadas en actividades de innovación. Obviamente, resulta complexo determinar para algunhas destas en que medida se deberían ao FT ou a outros factores contextuais. 
Ese balance de resultados é a consecuencia de toda unha serie de deficiencias detectadas na implementación do FT desde os seus inicios.

A execución dos Fondos FEDER en Galicia foi presentando un nivel moi baixo ao longo de case todo o período. A menor execución, con datos a mediados do ano 2015, producíase nos programas operativos de carácter plurirrexional, xestionados na meirande parte pola Administración estatal. Tanto foi así que, poñendo o foco no FT, só a metade do gasto fora executado. A xestión dos fondos presentou tamén rixideces, poñéndose algunhas de manifesto ao longo da crise económica. Desta maneira, a pesar da difícil situación económica os xestores atopáronse con limitacións como a imposibilidade de efectuar reprogramacións entre rexións, supoñendo que isto garantiría que os recursos chegasen aos territorios obxectivo. En adición, programas como o FT contaban unicamente con dous eixes de actuación, o que non facilitou a mobilidade de recursos entre eles e limitou a flexibilidade para a correcta atención das necesidades de aumento das capacidades de I+D+i e de vertebración do Sistema Galego de Innovación (creación de centros tecnolóxicos, de centros de innovación empresarial e espazos para a cooperación na innovación, ou atracción de multinacionais ao territorio, protagonismo das pemes na innovación, etc.). Por se isto non fose suficiente, o ritmo de execución do gasto dos restantes fondos FEDER ao longo do período tampouco se correspondía coas evidentes necesidades creadas pola fonda crise económica. Cómpre sinalar que a cuestión da problemática da execución non é atribuíble exclusivamente á xestión durante o período, senón que pode verse afectada por limitacións na capacidade de absorción dos fondos, pola crise económica, polo enfoque vertical de arriba a abaixo das políticas, que non facilitou a adaptación ás necesidades do territorio nese novo contexto, etcétera.

Un programa operativo plurirrexional como este foi deseñado e xestionado, como diciamos, desde a Administración central. O CDTI foi o principal executor de axudas, acompañado nesta tarefa principalmente, aínda que en menor medida, pola Secretaría General de Ciencia e Innovación do Ministerio de Economía e polo Instituto de Crédito Oficial. Se poñemos a atención no caso particular do CDTI, o principal organismo executor do FT, este instrumentalizou inicialmente a aplicación dos recursos a través de tres programas diferenciados: a Liña Directa de Innovación, o programa de Préstamos Directos á Innovación e o FEDER-Innterconecta, sendo este último o eixe principal de actuacións programadas para Galicia por este organismo. Este modelo de aplicación centralizada do FT dificultou a asunción de competencias de I+D+i por parte da Comunidade Autónoma, redundando na fixación de obxectivos de carácter xeneralista e agrandando a distancia física con respecto aos que deberían ser os teóricos beneficiarios das axudas, o que, alén das problemáticas detectadas, acentuaría os problemas de absorción de recursos do Sistema Galego de Innovación.

Con posterioridade ao período de vixencia do FT e no límite do período de xustificación diante de Bruxelas, incorporouse repentinamente un gran volume de gasto executado por outras vías. Na data 31/12/2015, e no último momento, a execución deste Programa situouse mesmo por riba da cifra de axuda asignada inicialmente, feito que só se pode cualificar como rechamante. Para acadar este fito incluíronse no FT, por exemplo, recursos destinados a convenios procedentes de programas "superavitarios" na execución como o de Economía Baseada no Coñecemento, entre outras actuacións que non sempre foron dirixidas a responder ás necesidades de evolución sistémicas.

No estudo da distribución sectorial dos recursos do FT, observouse que tiveron un gran peso as actividades relacionadas coa intermediación financeira, o apoio á industria manufactureira e outros servizos e as axudas á actividade inmobiliaria (Sande Veiga, 2018). Non obstante, no relativo ás tecnoloxías ambientais e á enerxía, dous sectores clave e con potencialidade en Galicia, o apoio non foi tan evidente. Por outra banda, en programas como Innterconecta evidenciouse un apoio importante ás TIC a través dos proxectos acometidos, tal e como se propoñía inicialmente, pero á vista do sinalado non parece que se incidise de maneira apropiada nos factores clave para afrontar os retos de futuro, tal e como se pretendía.

En definitiva, os datos contrastados permiten conxecturar que os instrumentos empregados pola Administración central como FEDER-Innterconecta (proxectos empresariais de importante dimen- 
sión), a compra pública innovadora empregada para Hospital 2050 e Innova Saúde ou os préstamos de grandes contías do ICO non foron os máis axeitados para lograr os obxectivos propostos, facendo que o protagonismo nas axudas virase cara ás grandes empresas en vez de cara ás pemes e que non se afondase na necesaria evolución das capacidades innovadoras e na vertebración do Sistema Galego de Innovación.

\section{Conclusións e recomendacións de política}

O importante volume de recursos asignados ao FT permitiu obter un certo número de resultados pero, en conxunto, foron moi modestos e están moi lonxe dos resultados esperados e espera bles.

A pesar da cantidade de recursos mobilizados a través do FT 2007-2013, a xestión centralizada e as problemáticas derivadas desta produciron uns pobres resultados que non permitiron o aproveitamento óptimo para a mellora das capacidades innovadoras galegas.

A concreción do obxectivo principal do FT consistía na estruturación do Sistema de Innovación para afrontar os retos futuros. Este obxectivo ía acompañado por unha serie de obxectivos intermedios cuxa proposta foi tamén revisada.

En canto ao primeiro deles, observamos que entre os anos 2007 e 2014 (e incluso ata o ano 2016) o esforzo total en I+D (gasto en I+D/PIB) decreceu en Galicia de forma continuada, retrocedendo a niveis dunha década atrás. En termos absolutos a caída foi moi considerable, desde 307 millóns de euros no ano 2007 a 223 millóns en 2015.

Para o segundo dos obxectivos, no que se procuraba o apoio a comportamentos empresariais innovadores, cómpre sinalar que o gasto total en innovación das empresas diminuíu ao longo do período. 0 número de empresas con actividades innovadoras caeu desde 1.745 empresas no ano 2007 a 924 en 2015; en lóxica correspondencia, tamén caeu o gasto total en innovación desde 965 millóns de euros a 462 millóns, para os mesmos anos, e tamén caeu o gasto medio en innovación por empresa desde 553 mil euros a 499 mil.

Por outra banda, o feito de dotar orzamento para o financiamento da I+D+i empresarial a través de convocatorias como Innterconecta permitiu que participasen neste tipo de actividades un número importante de pemes (en comparación cun escenario de ausencia de recursos); agora ben, nunha análise máis fonda sabemos que os proxectos aprobados -de tamaño medio ou medio/grande, polo xeral- están dirixidos e liderados en moitas ocasións por grandes empresas, relegando ás pemes a un papel secundario cando non de meros acompañantes.

No terceiro dos retos, centrado no apoio á transferencia de resultados, obsérvase no deseño do FT a existencia de liñas de axuda destinadas a estas tarefas como as recollidas polos Temas 4-Axudas a I+DT, Tema 6-Axudas a pemes ou Tema 7-Investimento en I+I, e algunhas delas contando con importantes recursos. Outra cuestión é se estes recursos serviron para promover a innovación no sistema produtivo -o número de empresas innovadoras caeu en Galicia a menos da metade ao longo dese período-.

A atracción de pemes á actividade innovadora non acaba por ter o papel relevante que podería alcanzar coas contías propostas. Aínda máis, o feito de que os proxectos aprobados teñan unha dimensión importante produce que estes pivoten tendo como centro os intereses de entidades empresariais de maior dimensión, de maneira que non se produciría unha verdadeira mobilización dos axentes pretendidos ao relegalos a un segundo plano.

Outro dos obxectivos aos que se facía mención no documento do FT é a igualdade entre mulleres e homes no campo da I+D+i. Se ben nos últimos anos se produciron melloras neste ámbito, resulta complicado atribuír estes cambios sociais a un programa no que gran parte das axudas non recollían este criterio, tal e como aconteceu en convocatorias como Innterconecta, nos grandes préstamos do ICO ou na dotación de infraestruturas de $\mathrm{I}+\mathrm{D}$, entre outras. 
Continuando co foco nos obxectivos fixados no FT, cómpre subliñar o feito de que dúas das debilidades do Sistema de Ciencia e Tecnoloxía, como son a escasa formación dos RR.HH. en I+D+i ou a necesidade de fomento da cultura innovadora, non teñan un traslado máis claro en canto a metas para acadar.

Polo que respecta á articulación do sistema, as axudas do FT serviron para aumentar a colaboración e a cooperación entre os distintos organismos públicos de investigación, centros tecnolóxicos e empresas, pero esas colaboracións parecen estar circunscritas a eses proxectos puntuais e non teñen continuidade no tempo. Alén diso, o uso destas axudas non amosa resultados en canto á creación de novos centros de innovación empresarial. Por outra banda, si se observa a atracción de empresas doutras CC.AA. para participar nas convocatorias, pero isto tampouco se traduce na atracción dos seus centros innovadores a Galicia.

Ademais, resulta difícil poder afirmar que a través do FT exista unha mellor articulación do sistema cando a propia Administración Pública galega ou as universidades tiveron un papel menor na súa execución. De feito, o FT foi instrumentado a través do Eixe 1 do FEDER -dirixido ao apoio empresarial- e non a través do Eixe 2 -destinado especificamente á vertebración do sistema de innovación-.

En todo caso, a análise do proceso de implementación mostra as consecuencias negativas da xestión centralizada do FT. Neste sentido, parece claro que o deseño centralizado e a estrutura de xestión controlada de xeito absoluto desde a Administración central, co CDTI como principal executor das axudas pero cunha maraña complexa de organismos, contribúe a explicar a tardanza en arrancar a execución do FT, a pouco acertada orientación das actuacións, o baixo nivel de execución real e, finalmente, os mediocres resultados. Este modelo de aplicación centralizada do FT dificultou a asunción de competencias de I+D+i por parte da Comunidade Autónoma, redundando na fixación de obxectivos de carácter xeneralista e agrandando a distancia física con respecto a quen deberían ser os teóricos beneficiarios das axudas, e acentuou os problemas de absorción de recursos do Sistema Galego de Innovación.

En definitiva, os datos contrastados permiten conxecturar que os instrumentos empregados pola Administración central como FEDER-Innterconecta (proxectos empresariais de importante dimensión), a compra pública innovadora empregada para Hospital 2050 e Innova Saúde, ou os préstamos de grandes contías do ICO non foron os máis axeitados para lograr os obxectivos propostos, facendo que o protagonismo nas axudas virase cara ás grandes empresas en vez de cara ás pemes e que non se afondase na necesaria evolución das capacidades innovadoras e na vertebración do Sistema Galego de Innovación.

Á vista dos resultados do estudo propóñense algunhas recomendacións de carácter xeral, que serán de utilidade para a planificación e implementación de políticas de innovación de cara ao futuro na Comunidade Autónoma.

En primeiro lugar, resulta altamente recomendable o desenvolvemento e a asunción real do disposto na normativa estatutaria para o marco de competencias de I+D+i en Galicia, co fin de deseñar, planificar, implementar e avaliar de forma máis eficaz e eficiente as estratexias, instrumentos e recursos para a innovación atendendo ás necesidades e características do territorio. Tal e como apunta a literatura sobre sistemas rexionais de innovación relacionada na segunda epígrafe deste artigo, non se debe perder de vista que a capacidade nacional de innovar depende da adaptación das institucións e políticas ás características e pautas de funcionamento dos axentes dese territorio, e do grao de coñecemento, confianza e facilidade de coordinación, aspectos todos que, de acordo co principio de subsidiariedade, aconsellan que sexan as institucións máis próximas as que asuman a responsabilidade do deseño e xestión dos programas.

Así mesmo, é necesario que as políticas de innovación se deseñen e apliquen de maneira que se limite ou minimice a problemática detectada das fugas de recursos cara outros territorios.

Por último, é aconsellable incrementar a importancia dos procesos avaliadores das políticas de innovación implementadas no territorio nas súas distintas fases de aplicación, para o que cómpre sinalar nelas obxectivos máis específicos. Estes procesos deberán realizarse con rigor e tamén á marxe do arbitrio das autoridades planificadoras para garantir a súa imparcialidade. 


\section{Bibliografía}

Ahn, J.M., Minshall, T., e Mortara, L. (2015). Open innovation: A new classification and its impact on firm performance in innovative SMEs. Journal of Innovation Management, 3(2), 33-54.

DOI: http://dx.doi.org/10.2139/ssrn.2431205

Aiello, F., e Pupo, V. (2012). Structural funds and the economic divide in Italy. Journal of Policy Modeling, 34(3), 403-418. DOI: https://doi.org/10.1016/j.jpolmod.2011.10.006

Asheim, B. (2006). Constructing regional advantage. Principles, perspectives, policies. Final report. Brussels, Belgium: European Comission, DG Research. Recuperado de https://www.dime-eu.org/files/active/0/regional advantage FINAL.pdf

Asheim, B., Moodysson, J., e Tödtling, F. (2011). Constructing regional advantage: Towards state-of-the-art regional innovation system policies in Europe? European Planning Studies, 19, 1133-1139. DOI: https://doi.org/10.1080/09654313.2011.573127

Audretsch, D. (1998). Agglomeration and the location of innovation activity. Oxford Review of Economic Policy, 14(2), 18-29. DOI: https://doi.org/10.1093/oxrep/14.2.18

Barca, F. (2009). An agenda for a reformed cohesion policy. A place-based approach to meeting European Union challenges and expectations. Regional Policy European Commision. Recuperado de http://www.europarl.europa.eu/meetdocs/2009 2014/documents/regi/dv/barca report/barca report en. pdf

Basile, A. (2012). Evaluating R\&D networking to revitalize SMEs innovative performances: a management perspective. Business: Theory \& Practice, 13(3), 217-227. DOI: https://doi.org/10.3846/btp.2012.23

Boschma, R. (2005). Proximity and innovation: A critical assessment. Regional Studies, 39(1), 61-74. D0I: https://doi.org/10.1080/0034340052000320887

Boschma, R. (2009). Evolutionary economic geography and its implications for regional innovation policy. Paris, France: OECD. Recuperado de http://econ.geo.uu.nl/boschma/OECD.pdf

Breinlich, H., Ottaviano, G., e Temple, J. (2014). Regional growth and regional decline. En P. Aghion e S. Durlauf, Handbook of economic growth, vol. 2B, Ch. 4 (pp. 683-779). London, England: London School of Economics. DOI: https://doi.org/10.1016/B978-0-444-53540-5.00004-5

Brujin, P., e Lagendijk, A. (2005). Regional innovation systems in the Lisbon strategy. European Planning Studies, 13(8), 1153-1172. DOI: https://doi.org/10.1080/09654310500336519

Camagni, R., e Capello, R. (2012). Regional innovation patterns and the EU regional policy reform: Towards smart innovation policies. 52nd ERSA Conference. Bratislava (Slovakia), August 21-24. ERSA.

Cardenete, M., e Delgado, M. (2013). Analysis of the impact of the European Funds in Andalucia in 2007-2013 Using a general equilibrium model. Business and Economics, 4(6), 448-452.

DOI: https://doi.org/10.4236/me.2013.46047

CDTI (2013). Fondo FEDER Innterconecta. Recuperado de http://www.cdti.es/index.asp?MP=100\&MS=806\&MN=2

Comisión Europea. (2010). Comunicación de la Comisión al Parlamento Europeo, al Consejo, al Comité Económico y Social Europeo y al Comité de las Regiones: Contribución de la Política Regional al crecimiento inteligente en el no marco de Europa 2020. COM/2010/0553 final. Bruxelas, Bélxica: Comisión Europea. Recuperado de https://eur-lex.europa.eu/legal-content/ES/TXT/?uri=CELEX:52010DC0553

Comisión Europea (2011). Regional policy for smart growth in Europe 2020. Brussels, Belgium: Directorate Genral for Regional Policy, EU Publications Office. Recuperado de https://ec.europa.eu/regional_policy/sources/information/pdf/brochures/rfec/2011 smart growth en.pdf

Cooke, P. (1998). Introduction: Origins of the concept. En H. Braczyk, P. Cooke e M. Heidenreich (Eds.), Regional innovation systems (pp. 2-25). London, England: UCL Press.

Cooke, P. (2012). Relatedness, transversality and public policy in innovative regions. European Planning Studies, 20(1), 1889-1907. DOI: https://doi.org/10.1080/09654313.2012.723426

Cooke, P. (2018). Transversality, resilience and innovation: A qualitative regional analysis. En T. Baycan e H. Pinto (Eds.), Resilience, crisis \& innovation dynamics, Ch. 7 (pp. 130-150). Edward Elgar. DOI: https://doi.org/10.4337/9781786432193.00014

Dall'erba, S., Guillain, R., e Le Gallo, J. (2009). Impact of structural funds on regional growth: How to reconsider a 9 year-old black box. Region and Development, 30, 77-100. Recuperado de http://region-developpement.univ-tln.fr/fr/pdf/R30/8-Dall\%27erba Guillain Le\%20Gallo.pdf 
Foray, D., e Van Ark, B. (2007). Smart specialisation in a truly integrated research area is the key to attracting more R\&D to Europe. Knowledge Economists Policy Brief, 1. Recuperado de https://ec.europa.eu/invest-in-research/pdf/download en/policy brief1.pdf

Foray, D., David, P., e Hall, B. (2009). Smart specialisation-The concept. Knowledge Economist Policy Brief, 9. Recuperado de https://ec.europa.eu/invest-in-research/pdf/download en/kfg policy brief no9.pdf

Fornahl, D., Broekel, T., e Boschma, R.A. (2011). What drives patent performance of German biotech firms. The impact of R\&D subsidies, knowledge networks and their location. Papers in Regional Science, 90(2), $395-418$. DOI: https://doi.org/10.1111/j.1435-5957.2011.00361.x

Hollanders, H., Es-Sadki, N., e Kanerva, M. (2016). Regional innovation scoreboard 2016. Maastrich, Netherlands: InnoMetrics-Merit, European Comission.

INE. (2017). Población de las CC.AA. Recuperado de http://www.datosmacro.com/demografia/poblacion/espana-comunidades-autonomas/galicia

Isaksen, A. (2001). Building regional innovation systems: Is endogenous industrial development possible in the global economy? Canadian Journal of Regional Science, XXIV(1), 101-120. Recuperado de http://www.cjrs-rcsr.org/archives/24-1/ISAKSEN.pdf

Jurevičienė, D., e Pileckaitė, J. (2013). The impact of EU structural funds support and problems of its absorption. Business Management and Education, 11(1), 1-18. DOI: https://doi.org/10.3846/bme.2013.01

Koschatzky, K. (1997). Technology based firms in the innovation process. Management, financing and the regional networks. Heidelberg, Germany: Physica.

Landabaso, M. (2011). Qué políticas pueden o no contribuir al desarrollo regional. En J. Curbelo, M. Parrilli e F. Alburquerque (Coords.), Territorios innovadores y competitividad (pp. 493-511). Madrid: Marcial Pons. Recuperado de https://dialnet.unirioja.es/servlet/libro?codigo=477871

Lembcke, A., e Menon, C. (2017). Making policy evaluation work: The case of regional development policy. $O E C D$ Science, Technology and Industry Policy Papers, 38, 2-35. Recuperado de https://www.oecd-ilibrary.org/docserver/c9bb055fen.pdf?expires=1568472565\&id=id\&accname=guest\&checksum=D6F340FFF106228F1836708369BAEC58

Lundvall, B.-A. (1992). National systems of innovation. London, England: Pinter.

Martin, R., e Trippl, M. (2013). System failures, knowledge bases and regional innovation policies. CIRCLE Working Papers, 2013/13. Lund, Sweden: Centre for Innovation, Research and Competence in the Learning Economy (CIRCLE). Lund University. Recuperado de http://wp.circle.lu.se/upload/CIRCLE/workingpapers/201313 Martin_Trippl.pdf

McCann, P., e Ortega-Argilés, R. (2011). Smart specialisation, regional growth and applications to EU Cohesion Policy. Documents de Treball de l'IEB, 2011/14. Barcelona: Institut d'Economia de Barcelona. Recuperado de http://www.ub.edu/ubeconomics/wp-content/uploads/2012/02/Doc2011-141.pdf

McCann, P. e Rodríguez-Pose, A. (2011). Why and when development policy should be place-based. En OECD (Ed.), OECD Regional Outlook 2011: Building resilient regions for stronger economies (pp. 203-214). París, France: OECD.

Ministerio de Economía y Hacienda. (2007). Programa Operativo de I+D+i por y para el beneficio de las empresas-Fondo Tecnológico 2007-2013. Madrid: Ministerio de Economía y Hacienda. Recuperado de http://www.dgfc.sepg.hacienda.gob.es/sitios/dgfc/esES/ipr/fcp0713/c/oacag/Documents/investdesarrinnov.pdf

Nauwelaers, C., e Wintjes, R. (2003). Towards a new paradigm for innovation policy? En B. Asheim, A. Isaksen, C. Nauwelaers e F. Tödtling (Eds.), Regional innovation policies for small-medium enterprises (pp. 193-220). Cheltenham, UK/Lyme, US: Edward Elgar.

Neumark, D., e Simpson, H. (2015). Place-based policies. En G. Duranton, J. Henderson e W. Strange (Eds.), Handbook of regional and urban economics, vol. 5, Ch. 18 (pp. 1197-1288). Amsterdam, Netherlands: Elsevier.

OECD (2011). Reviews of regional innovation-Regions and innovation policy. Paris, France: OECD.

Papaconstantinou, G., e Polt, W. (1997). Policy evaluation in innovation and technology: An overview. OECD Conference Policy Evaluation in Innovation and Technology: Towards Best Practices. Paris, France: OECD. Recuperado de http://www.oecd.org/sti/inno/2347559.pdf

Remeikiene, R., e Gaspareniene, L. (2016). Evaluation of the impact of the EU structural support on the competitiveness of Lithuanian economics. Centr. Eur. J. Public Policy, 10(1), 1-11.

DOI: https://doi.org/10.1515/cejpp-2016-0019

Sande Veiga, D. (2018). Avaliación do programa FEDER-Innterconecta do Fondo Tecnolóxico 2007-2013 en Galicia. (Tese de doutoramento). Santiago de Compostela: Universidade. 
Schmidt, C. (2001). Knowing what works. The case for rigorous programme evaluation. London, England: Centre for Economic Policy Research (CEPR). Recuperado de https://papers.ssrn.com/sol3/papers.cfm?abstract id=273173

Tödtling, F., e Trippl, M. (2005). One size fits all?: Towards a differentiated regional innovation policy approach. Research Policy, 34(8), 1203-1219. DOI: https://doi.org/10.1016/j.respol.2005.01.018

Vence, X. (2007). Crecimiento y políticas de Innovación. Madrid: Pirámide

Vence, X. (Dir.). (1998). La política tecnológica comunitaria y la cohesión regional. Los retos de los sistemas de innovación periféricos. Madrid: Civitas

Žalevičienè, A. (2012). Regional policies and the EU structural support: Evaluation of the experience. Economics and Management: Current Issues and Prospects, 2(26), 44-53. 